\title{
12
}

\section{Handling Languaging During Empirical Research: Ethnography as Action in and Across Time and Physical-Virtual Sites}

\section{Sangeeta Bagga-Gupta, Giulia Messina Dahlberg, and Annaliina Gynne}

\section{Introduction and Aim}

A growing body of literature recognizes the inappropriateness of conceptualizing and representing communicative practices in terms of fixed codes where different named languages mutually exclude one another. This could also be expanded to the study of embodiment where gestures and other semiotic resources have come to play a central role in scholarly

S. Bagga-Gupta ( $\bowtie)$

School of Education and Communication, Jönköping University, Jönköping, Sweden

e-mail: sangeeta.bagga-gupta@ju.se

G. Messina Dahlberg

Department of Education and Special Education, University of Gothenburg, Gothenburg, Sweden

\section{A. Gynne}

School of Education, Culture and Communication, Mälardalen University, Västerås, Sweden 
writing only relatively recently (Finnegan, 2015; Linell, 2009). When dealing with educational research in which the units of analysis consist of social interaction across (analogue-digital) settings, there is also a need to be reflexive while attending to what we do as researchers. Furthermore, post the digital-technological explosion, people's communicative practices have changed drastically at the global as well as the local levels (Leandri \& Neumann, 2014). The point that is salient is that capturing a moving object empirically, that is, a phenomenon occurring at the boundaries of different physical-virtual sites, requires particular analytical attention and methodological creativity.

Academic scholarship has contributed in important ways to our understandings of human beings — children and adults' — use of (primarily oral) talk, body orientations, such as gaze and gestures, and the semiotic affordances of tools in different settings (Finnegan, 2015; Goodwin, 1994; Jewitt, 2009; Linell, 2009; Machin, 2013). Some of this focus is more recently being directed towards learning as well as communicative practices, or languaging more generally (Kress, 2003; Linell, 2009; Paulasto, Riionheimo, Meriläinen, \& Kok, 2014). This type of scholarship has furthered our understandings of embodiment and the materiality of human talk-centred communication in different settings, including more recently in institutional learning arenas (see, e.g., Goico, 2019; Gynne, 2016; Holmström, 2013; Messina Dahlberg, 2015; St John, 2014; Tapio, 2013). The role of written-communication and communication where more than one language-variety are deployed is, however, only sparingly centrestaged in much of the existing literature. Moreover, here the role of an oral-language bias and a monolingual bias is being increasingly flagged (Bagga-Gupta, 2012a, 2017a, 2017b, 2017c; Gal \& Irvine, 1995). Another issue that is relevant for present purposes is the demarcated nature of scholarship within the language sciences and the bearing this has in the domain of educational research. In general, written-communication is focused upon in literacy scholarship, and the use of more than one language-variety has traditionally been considered as the "property" of the domains of bilingual studies, Second Language Acquisition (SLA), foreign languages etc. (Bagga-Gupta, 2012a, 2014a, 2017c, 2019a, b; Deters, Gao, Miller, \& Vitanova-Haralampiev, 2014; Pitkänen-Huhta \& Holm, 2012). Furthermore, contributions from the scholarship that focus on the 
modality heterogeneity of signed communication also continue to be conducted in separate academic domains and remain, for the most, eclipsed from the mainstream academic scholarship.

This chapter contributes in two ways to the different areas of research presented above. First, by investigating the ways in which the demarcations of the scholarship domains can be addressed, and second, by illustrating the challenges and opportunities of (n)ethnographic work in the study of phenomena that cannot/should not be framed and limited in terms of specific areas across time and space. Scholarship gives recognition to the fact that fieldwork is undergoing changes rapidly (Fabion \& Marcus, 2009; Horst \& Miller, 2012). The latter specifically address the implications of digitalization of everyday practices (not least in educational settings) as well as research practices in (n)ethnographic fieldwork $^{1}$ and scholarly writing. This chapter highlights the need for ethnographically inclined researchers working in domains such as communication, culture and diversity to pay greater reflexive attention to their fieldwork, analysis and writing collaborative practices. To this end, we attend to three epistemological and practical challenges that reflect significant methodological issues currently in the very doing of (n)ethnographic fieldwork. It is these challenges that constitute the aims of this chapter.

1. First, we analytically frame ethnographic methods and data in terms of where, when and what is the field and data by discussing how (and for what purposes) the boundaries of the field(s) are constructed; this includes ethical issues that arise when the possibilities afforded by participants' trajectories across physical-virtual spaces change the kinds of (ethnographic) research that are possible to conduct.

2. Second, by using a range of representational techniques, we illustrate the ways in which multimodal analysis across physical-virtual sites can contribute towards meeting challenges related to research methodological practices.

\footnotetext{
${ }^{1}$ The analyses presented in this chapter highlight that (n)ethnography as a term is well suited for describing how the practices of netnography and ethnography "work in concert to illuminate new issues in the social sciences" (Kotzines, 2010, p. 58).
} 
3. Finally, we explicitly illustrate and discuss the role of the researcher during as well as beyond fieldwork phases. Focusing reflexivity, we discuss the choices and challenges we (continue to) face, during fieldwork, analysis and writing phases (both during collaborative and during individual writing).

This chapter attempts to go beyond the biases and gaps highlighted above and takes a point of departure in the multidisciplinary work that we have been involved in, since the 1990s, in different ethnographically framed research projects. While our projects were previously framed in analogue terms (in that the field was primarily physical and research methods deployed analogue technologies), a digital presence marks both the fields of engagement and the tools of recording and data generation since the turn of the century. Our interests focus upon a range of ethnographical methods that attempt to analytically engage with representations of human communication including its visual, auditory, manual and semiotic dimensions.

By bringing together data from different (n)etnographic projects where participants use more than one language-variety ${ }^{2}$ and more than one modality, ${ }^{3}$ the study presented in this chapter makes visible the complexities of languaging inside, outside and across (virtual) learning sites. Related to the study's first challenge, having access to multi-sited and multiple projects brings forth the issue of boundary framings of the field(s), data, participant(s) and researcher trajectories. The second challenge attended to relates to the representational techniques in scholarly writing; stretching the boundaries of interaction analysis and reporting, this chapter highlights the diversity of human languaging and identity positions (see Sect. 2). Discussing the challenges involved in conducting fieldwork, analysis and reporting where the data is multifaceted and complex, involves making visible the dynamics of languaging itself. The third challenge attended to in this study deals with the very issues related to reflexivity, including creativity, in the various phases of (n)ethnography.

\footnotetext{
${ }^{2}$ The range of named language-varieties covered in these projects include English, Finnish, Gujarati, Hindi, Italian, Marathi, Swedish, Swedish Sign Language.

${ }^{3}$ Oral, written, signed, pictorial, embodied, visually oriented modalities etc.
} 
Examining these by juxtaposing experiences across projects opens up for meta-analytical framings that can transgress monodisciplinary framed analysis and reporting. This means that analytical issues by default call for attending to and engaging with the specificities of a number of different individual academic domains (e.g. literacy, bilingualism, signed communication and foreign languages) in the language and educational sciences simultaneously.

The remainder of this chapter is structured as follows: Sect. 2 presents the theoretical framings on performing (n)ethnographic research across the twentieth and twenty-first centuries. Tenets of sociocultural, dialogical and decolonial perspectives are highlighted as the main premises for our thinking when the analytical focus is set on languaging and doing research. In Sect. 3, the data and the projects that we draw upon in the analysis are presented. Section 4 focuses upon the analysis of epistemological, pragmatic and analytical challenges in the doing of (n)ethnographic research by discussing research as action. In its three sub-sections, boundary framings across physical-virtual research fields, issues of data-creation and representations and researcher's positionings are analytically highlighted. In the final section of this chapter, the complexity of research as practice is discussed from a critical and reflexive perspective.

\section{On Performing Research: Theoretical Framings}

Framed in sociocultural, dialogical framings and decolonial perspectives, this chapter presents a study that builds upon our collective and cumulative experiences of doing (n)ethnographically framed research in multisited projects that have been, and are being, conducted in different geopolitical and digital spaces. A key premise in sociocultural and dialogical framings is that learning or socialization is conceptualized in terms of a situated and distributed process (Lave \& Wenger, 1991; Säljö, 2005; Vygotsky, 1962; Wertsch, 1998, 2002) where communication-irrespective of whether this occurs in one or more named language-varieties and modalities - is collaboratively achieved. Thus, participation and social 
interaction are understood as key aspects of human ontological development. ${ }^{4}$ Furthermore, communication is understood as being a significant dimension of the construction of human realities, rather than being a conduit that in some neutral sense mirrors reality. A key issue that Berger and Luckman's treatise, from 1966, on "The Social Construction of Reality" highlights, is the significance of the mundaneness of everyday existence, that is, the social practices in which humans and their actions are embedded. Such a premise implies that the analysis of everyday life must refrain from "any causal or genetic hypothesis, as well as from assertions about the ontological status of the phenomena analysed" (Berger \& Luckman, 1966, p. 34). This type of fundamental premise has a significant bearing upon how we, as scholars, approach and handle the research enterprise itself. Thus, how social practices in general and languaging in particular are handled during fieldwork or "data generation" processes and analysis is important to focus upon.

Action-oriented concepts like languaging that build upon the key premises of a sociocultural, dialogically framed perspective, can be understood in terms of constituting renewed attempts by scholars to sidestep monological and static understandings that mark an essentialist, bounded notion of language (Linell, 2009; see also Bagga-Gupta \& Messina Dahlberg, 2018). It is thus within the matrix of mundane interactions of everyday life that conventions are established (Berger \& Luckman, 1966). Here patterned norms eventually become transparent, taken for granted, and constitute the very fabric of human existence. Scholarship that takes such a position as a point of departure highlights, at least in a theoretical sense, the need to address the complex heteroglossic (Bakhtin, 1981) nature of communication and to unravel such patterns.

With the above as backdrop, the following issues are salient for present purposes. Monolingual positions in the scholarship and in institutional learning contexts continue (in large parts of the global-North at least) to obscure the fact that the large majority of the people in the

\footnotetext{
${ }^{4}$ See, for instance, the work by Merlin Donald (2001) where the concept of hybrid minds refers to the inextricable connections and interdependence between human cognition and culture, through the use of semiotic tools, in and through languaging.
} 
world live their lives while engaging with and deploying resources from more than one named language-variety (Gal, 2007). Significant here is that boundaries between named language-varieties and modalities are not of prime concern in the nitty-gritty communicative actions of human beings wherein meaning-making is key. ${ }^{5}$ This colonial linguacentrism furthermore, only in a limited manner, recognizes the routine ways of meaning-making inside, outside and across institutional settings. A decolonial perspective postulates that these settings are not only rich sites for research, but that languaging needs to be attended to from such complex points of departure in the research enterprise itself (Bagga-Gupta, 1995, 2013, 2019b; Garcia, 2009). This, as we have argued previously, highlights the need for promoting "critical multilingual and participatory perspectives [that] themselves make up marginal positions in the bilingual research landscape" (Bagga-Gupta, 2012, p. 88). This means, for instance, that there is merit in the researchers' experiences related to the named language-varieties and modalities deployed in the settings they explore. Critical reflections regarding issues of "othering", including the uncritical manner in which the language-varieties of the peoples in focus were (and continue to be) handled in the days when anthropology routinely used interpreters to understand the new spaces they studied, emerged only in the post WW II era (Asad, 1986; Fabian, 1983). Despite the near cult status of scholarly texts like Clifford and Marcus (1986) "Writing Culture", a self-critical stance has not spilled over onto ethnographies everywhere. For instance, newer discussions on translations highlight the continuing lack of reflexivity in the field with regard to representations:

\footnotetext{
${ }^{5}$ It is in the meaning-making enterprise of human languaging that boundaries are insignificant and inconsequential for people. This does not mean that boundaries are not significant in the political and ideological work that individuals and communities are engaged in, for instance, to get recognition, as users of a specific named language-variety or modality that is (for any number of reasons) marginalized in different geopolitical spaces. Thus, it is the tension between the routine ways-ofbeing-with-words (Bagga-Gupta, 2014a) where meaning-making is central against the backdrop of political/ideological segregation of specific named language-varieties or modalities that exclude people or communities that we attempt to illuminate in this chapter.
} 
Ethnography always involves translation, and usually in the narrowest sense of making words in one language accessible to speakers of another; yet even the new, or 'postmodern', ethnographers make little or no mention of the epistemological and political difficulties translating carried with it. (Sturge, 1997, p. 21)

Furthermore, Sturge (1997) highlights the duality of ethnographic translation,

from the oral to the written form as well as from one language to another; the reproduction of the performative aspects of an utterance-its physical, temporal and social contextuality-defies the translator's supposed task of reproducing meaning intact [...] ethnographic translation is faced with 'raw' words hovering around the mouths and ears that produced them. (p. 22)

Such a line of thought validates a reflexive position as well as a critique of the assumed neutralness of translation-based ethnographic research. For present purposes, our point is that a theorizing related to a sociocultural perspective needs to bring centerstage the importance of scholars' own language experiences with the named language-varieties and modalities deployed in the communities and by the peoples they study (Hoppers, 2009).

Another key theoretical idea that frames an action-oriented, sociocultural and dialogical perspective builds upon the mediational role attributed to cultural tools that have emerged phylogenetically and that are appropriated ontogenetically (Säljö, 2012; Vygotsky, 1934/1962; Wertsch, 1998). The recognition accorded to the symbiotic relationship between cultural tools (like language - the tool of tools) and people in inter-action with one another has given rise to hyphenated concepts in the sociocultural scholarship. Such concepts attempt to explicitly challenge the boundary-marked nature that dominates understandings of individuals, tools and named language-varieties and modalities. However, while the rich potentials and dimensions of languaging in concert with intellectual and material tools are recognized theoretically, attention in analysis and academic reporting has - as highlighted above- been dominated by an oral language bias and by a monolingual 
bias (Gramling, 2016). Thus, we argue, the multi-layered complex endeavour of languaging has not been given analytical emphasis in relation to the study of human meaning-making wherein recognition and visibility are accorded, at the level of data representation, to the composite irreducible nature of individuals in concert with tools.

Furthermore, an attempt is made to centre-stage power differentials in social practices empirically in this study from a decolonial framing (Comaroff \& Comaroff, 2009; Daiute, 2015; Fanon, 1961; Mignolo, 2012). Cultivating a decolonial imagination (Savransky, 2017) implies going beyond the hegemonies of namism (where references to key postcolonial texts circulate in the European scholarship) and "academic branding" (Pavlenko, 2017; where some neologisms have gained currency in the twenty-first century; see also Bagga-Gupta \& Messina Dahlberg, 2017, 2018). Namism has tended to fix issues of power differentials in terms of historically colonized places and branding tends to cement ideologies even though concepts have been re-worded through alternative theorizing. Going beyond such popularized framings, we argue for recognizing decolonial perspectives in terms of a paradigm where it is the here and now in all spaces - east/south and west/north, including physical-virtual spaces - that are important (Bagga-Gupta, 2017c, 2019a, b) and where "academic terms" (as compared to "academic branding") build upon emically framed explorations of empirical data across time and space. Such a stance implies that analytical units of analysis cannot be reduced to bounded entities that build upon a recognition of "imagined" boundaries that demarcate communities, nations, individuals or named language-varieties and modalities.

These sociocultural, dialogical and decolonial intersecting theoretical positions are used to set the analytical focus on the performance of languaging and the ways-of-being-with-words that take into cognizance marginalized global-South epistemologies. The latter emerge from groundings in situated experiences of human beings, including researchers who study the former. We engage with the three aims or the challenges of the present study framed within these intersecting positions. In other words, we take these analytical framings as points of departure and illustrate the need for cross-disciplinary critical viewings and voicings in contemporary research. 


\section{On Data and Projects}

The projects that are included in the study presented here share an interest in observing, describing and interpreting social practices as they unfold in the everyday lives of people in and across settings. These include natural textual spaces which encompass individuals, communities and institutions across space and time. Empirical data from five multi-sited (n)ethnographic projects (see Fig. 12.1) where linguistic-modality diversity is a salient feature are drawn upon. Fieldwork in these projects has been conducted in different geopolitical contexts (the nation-states of Sweden and India) and digital-physical spaces.

The GTGS (Gender Talk Gender Spaces), DS (Deaf Studies), DIMUL (Doing Identity in and through Multilingual Literacy Practices), CINLE (Studies of everyday communication and identity processes in net-based learning environments) and PAL (Participation for all? School and postschool pathways of young people with functional disabilities) projects are

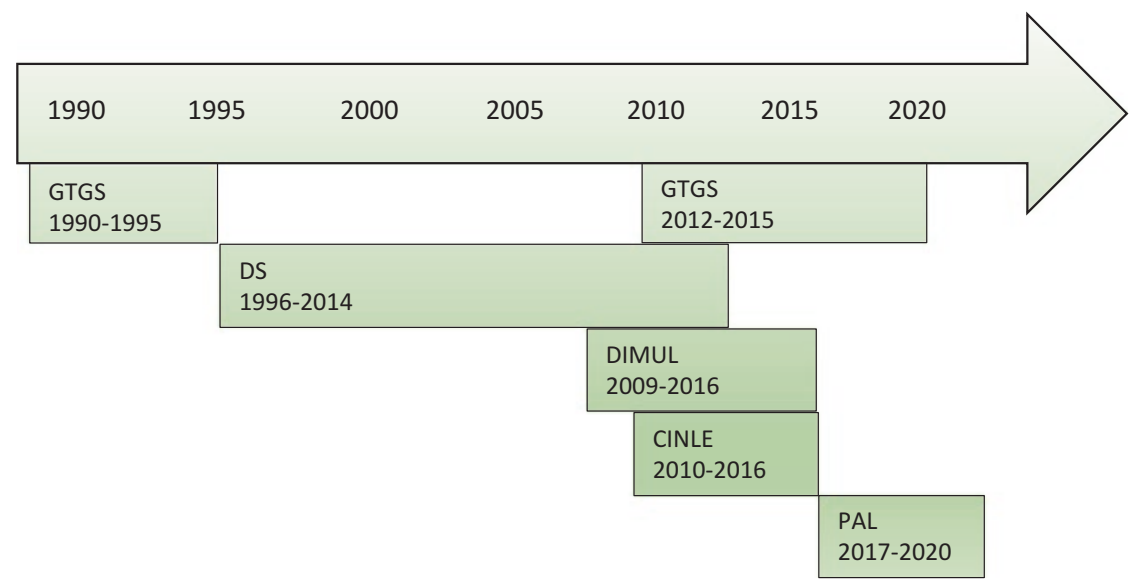

Fig. 12.1 Timeline for the projects which are engaged within the study (projects GTGS and PAL are ongoing, while fieldwork in projects DS, DIMUL and CINLE has concluded); data from project PAL are not used for illustrative purposes in this study 
situated at the CCD research group in Sweden. ${ }^{6}$ They are multi-sited, recently concluded and/or ongoing. They all draw upon data and experiences from and focus upon issues of learning and linguistic heterogeneity, inside, outside and across physical and virtual institutional spaces. Furthermore, they all share an ethnographic approach towards data generation. The specific data in these five projects consist of video-documentation, extensive fieldnotes, study materials, digital and/or analogue pictures, informal interviews and archive materials. Table 12.2 in the Appendix presents, apart from the nature of data, the language-varieties and modalities used by participants in the projects, the salient aims and results of each project. Table 12.1 presents an overview of the data that is upfronted from the different projects and that allows us to attend to the three key challenges that are focused upon in the present study.

Juxtaposing datasets from different projects is, as we have argued earlier, important since analysis across projects and datasets allows for rising above the specificities of individual projects. Moreover, this potentially allows for engaging with reflective discussions on the processes of

Table 12.1 Overview of the figures and issues dealt with in the analytical sections of the chapter

\begin{tabular}{llllll}
\hline Figure & Issue 1 & Issue 2 & Issue 3 & Project & Section \\
\hline 12.2 & $\mathrm{x}$ & - & - & - & 4.1 \\
12.3 & $\mathrm{x}$ & - & - & CINLE & 4.1 \\
12.4 & $\mathrm{x}$ & - & - & DIMUL & 4.1 \\
12.5 & $\mathrm{x}$ & - & - & DS & 4.1 \\
12.6 & $\mathrm{x}$ & $\mathrm{x}$ & - & DIMUL & 4.2 .1 \\
12.7 & $\mathrm{x}$ & $\mathrm{x}$ & - & DS & 4.2 .1 \\
$12.8,12.9,12.10$ & $\mathrm{x}$ & $\mathrm{x}$ & - & CINLE & 4.2 .1 \\
$12.11,12.12,12.13$ & - & $\mathrm{x}$ & - & GTGS & 4.2 .2 \\
12.14 & - & $\mathrm{x}$ & - & DS & 4.2 .2 \\
12.15 & - & - & $\mathrm{x}$ & CINLE & 4.3 \\
12.16 & - & - & $\mathrm{x}$ & DIMUL & 4.3 \\
$12.17,12.18$ & - & - & $\mathrm{x}$ & - & 4.3 \\
\hline
\end{tabular}

\footnotetext{
${ }^{6}$ The Communication, Culture and Diversity (CCD) network-based research environment at Jönköping University includes a number of research projects, in addition to those we draw upon here, that deal with issues of modality layered analysis. Of the five projects, fieldwork is currently ongoing in projects GTGS and PAL. Data is engaged with from all the projects, even though the present study does not illustrate data from project PAL.
} 
data-creation at a meta-level, including issues of categorization and analysis. Given that one of our important points of departure is that categorizations in themselves re-create identity positions (Bagga-Gupta, Hansen, \& Feilberg, 2017), a summary of the analytical or standard labels used in a field or those that arise in the analysis process (e.g. named language-varieties and modalities) do not in themselves promise neutrality or lend themselves an a priori fit into tables. Not reflecting upon this issue could in effect amount to a significant risk of falling into an essentialist trap. This constitutes another example of a challenge regarding how scholarship frames data pertaining to the boundaries that are drawn, for instance, for creating something as digital and something as physical or something as belonging to one named language-variety or modality and not another. This exemplifies the type of issues that are in themselves key analytical dimensions that we focus upon in the next analytical section.

\section{Research as Action: Challenges and Opportunities}

The first challenge focused upon in this study in the next sub-section discusses the tangible slipperiness related to where, what and when is "the field" in which we conduct fieldwork, and where, what and when is the very "data" that we scholars (have the possibility to) create today. Furthermore, Sect. 4 also highlights some of the representational issues that are salient in contemporary (n)ethnography (challenge two) and focuses upon issues related to the researcher's positionality across time and space in the field (challenge three).

\section{Where, What and When Is the Field? Boundary Framings Across Physical-Virtual Spaces}

A salient issue with regard to doing fieldwork-particularly in the twentyfirst century - has to do with where the boundaries of "the field" lie. In relation to the contours of the field, practical and ethical issues emerge 
since possibilities afforded by participants' trajectories across physical-virtual spaces change the type of data-creation that is possible. What is, then, multi-sited ethnography or research? According to Marcus (1995), a certain conception of fieldwork (in conventional terms, i.e. related to a specific community as well as space) gets lost in the attempt to include a variety of interests and therefore research questions that arise within multidisciplinary research. In particular, questions regarding locality are more often than not strictly bound with global dimensions, in which issues of temporality and spatiality take on new meanings, also for ethnographers (Horst \& Miller, 2009).

Figure 12.2 illustrates the trajectories in the five projects we have chosen as illustrative points of departure in and across the global and the local, as well as in and across virtual and physical spaces. These movements both within and across projects challenge the very doing of (n)ethnographic fieldwork currently. An analytical endeavour of tracing

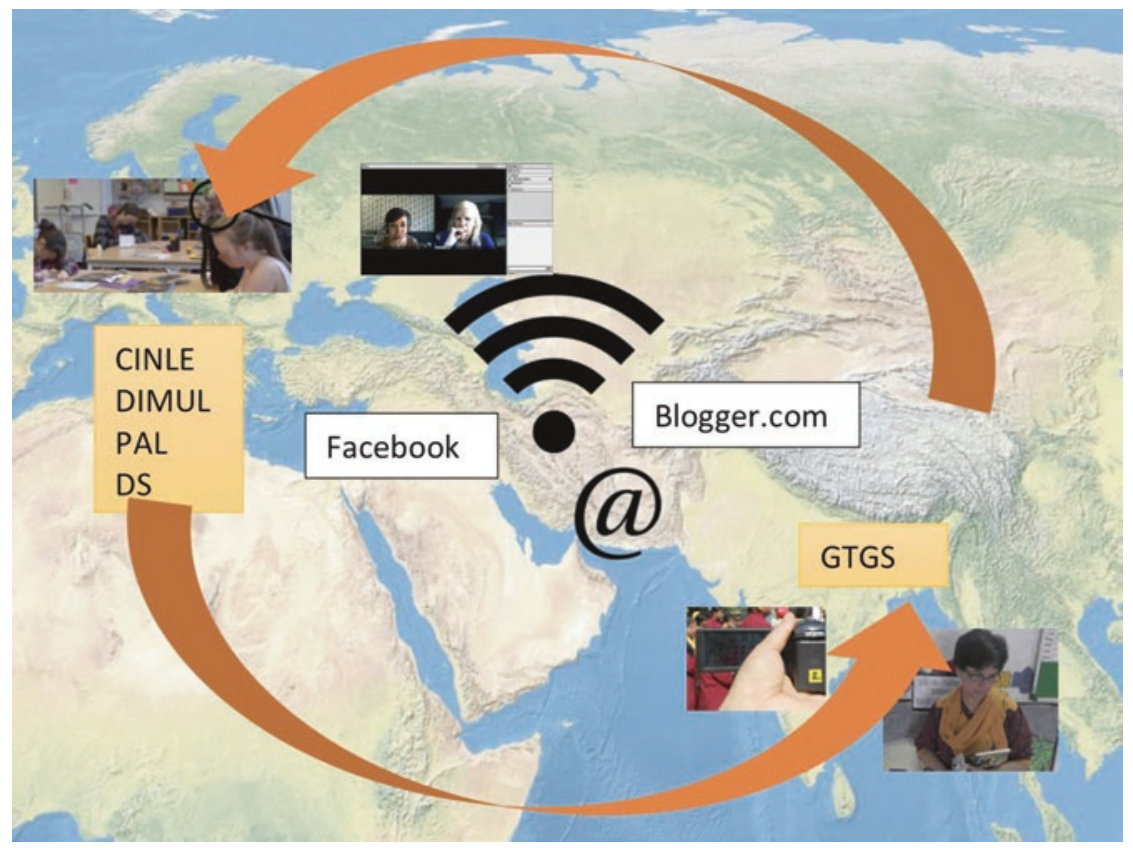

Fig. 12.2 Trajectories across physical-digital spaces in the five projects 
participant trajectories (as well as the trajectories of practices, linguistic items etc.) across time and spaces may be a challenge, which is why we see the need for bringing together ethnographic and netnographic approaches.

The data we use highlights a paradox wherein multi-sited research is currently made possible by the very digital technology that allows the researcher an immobility in terms of trips to physical field-sites across the globe. Some methodological challenges that ensure (and that we have encountered) during the course of designing fieldwork, data-creation and analysis illustrate this issue. For instance, what is the relationship between the spaces of interaction inside the physical world of the members participating in a university course, the videoconferencing digital space of the virtual classroom and "the field" where the researcher/s have spent hours watching the data, taking fieldnotes a posteriori (project CINLE)?

Being able to record institutional instructional meetings in project CINLE using a recording tool embedded in the videoconferencing platform Adobe Connect (and which we have, in our previous studies, referred to as the virtual classroom; see Fig. 12.3), meant that the researchers could take the position of a rather unobtrusive observer in the field. At the same time, the nature of the data allowed us to go back to "the field" as if we were present there and then, watching the interaction at the point of time it transpired. However, limitations in terms of the possibilities to be there with the dispersed students at each of their physical sites meant that we could not generate data regarding the participants' settings outside the virtual classroom. Despite this curtailment, we could perhaps bring a more emic perspective to the data, since we as researchers had the same limited access to the participants' physical contexts as they had to one another's settings during their online course meetings. In fact, an interesting analytical, as well as methodological, discussion emerged from our attempts to engage with the "fractured ecologies" (Luff et al., 2003) of online learning in general, including synchronous online learning activities. Such a fractured ecology of the online space of the virtual classroom (Messina 


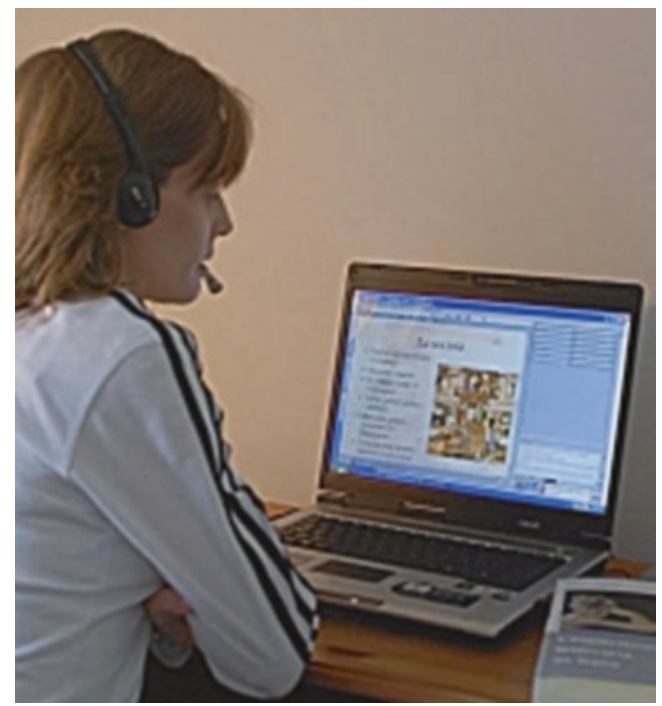

Fig. 12.3 Student sitting simultaneously at the desk and inside Adobe Connect: A video-conferencing environment (project CINLE)

Dahlberg \& Bagga-Gupta, 2015) in project CINLE challenged the position of the ethnographer as the "knowing observer", an issue that is salient in doing fieldwork in both analogue and digital spaces (Clifford \& Marcus, 1986). Clifford and Marcus (1986), way back in a pre-digital era, discuss this issue: a "conceptual shift, 'tectonic' in its implications, has taken place. We ground things, now, on a moving earth. There is no longer any place of overview" (Clifford \& Marcus, 1986 , p. 22). Such a shift is relevant for the kind of complex cultural descriptions that constitute a point of departure for doing fieldwork, when the field lies within the backyard or at the fingertips of the researcher's keyboard. Figure 12.3 illustrates a digital platform used by all language departments that offer online language courses at a Swedish university since 2007.

In addition to virtual classrooms designed for formal learning activities, the affordances of social media allow participants, as well as researchers (and in principle any human being with access to a device connected to the internet), a variety of ways of simultaneously being 


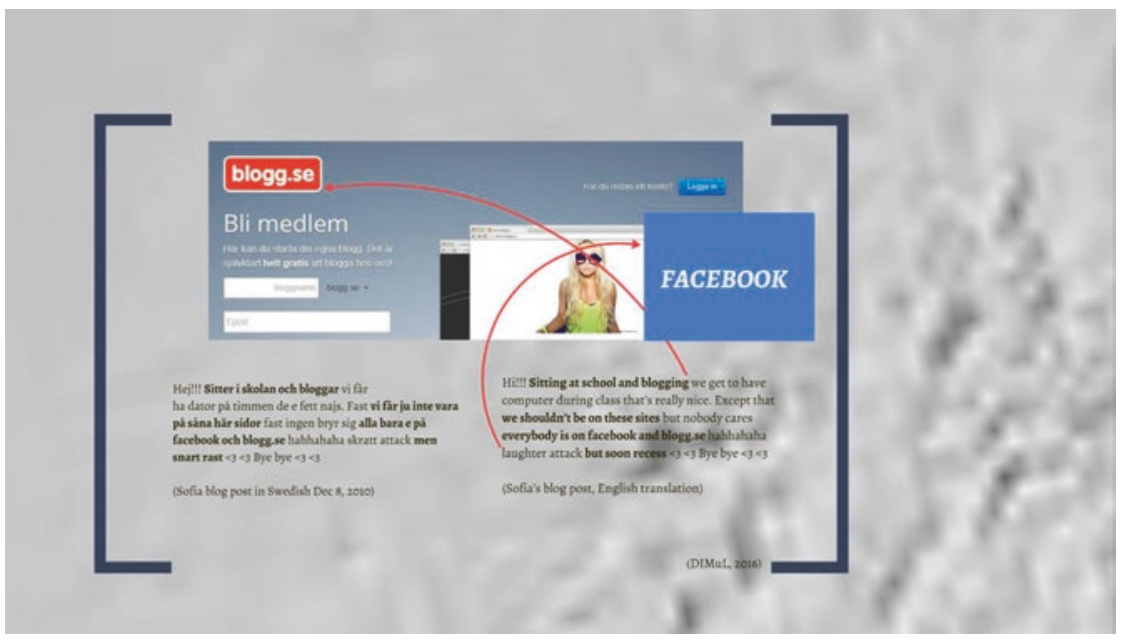

Fig. 12.4 Blog post as an illustration of (a) chaining and (b) crossing time and space (project DIMUL)

both here and there. Researcher and participant trajectories across time and space became an issue also in project DIMUL. Figure 12.4 illustrates an instance of a blog post, authored by 12 -year-old student Sofia. ${ }^{7}$ The blog post was authored on the one hand in the physical and temporal place of the school classroom during a lesson when we were doing fieldwork inside the classroom. It was simultaneously authored on the other hand inside a virtual blog portal called Blogg.se. The bold sections in Fig. 12.4 represent Sofia's presence in the physical space of the classroom, as well as her synchronous presence in the virtual world. She is "at school", "during class" and it's "soon recess", but at the same time, she is "blogging" "on these sites" (i.e. Blogg.se), and she is cognizant of the fact that the case is the same for her peers: "everybody is on facebook and blogg.se".

Figure 12.4 makes visible our analytical efforts to highlight the issues of what, where and when is the field emically. Furthermore, a blog text, representing a slice of everyday life in a specific context, also highlights

\footnotetext{
${ }^{7}$ All names used in this and our other projects are pseudonyms.
} 
how participants chain different named language-varieties and modalities in mundane languaging practices, an issue we deal with below.

Thus, while the fractured ecology of the research field emerges in a clear-cut manner when we deal with (n)ethnographic research, a final example that illustrates this challenge highlights the need to understand the field, including the fieldwork, in a more nuanced manner. Our next example reiterates the issue of what, where and when is the field, from fieldwork in one of our more recent DS projects. It highlights the physicality of the here and now. Figure 12.5 offers a vignette

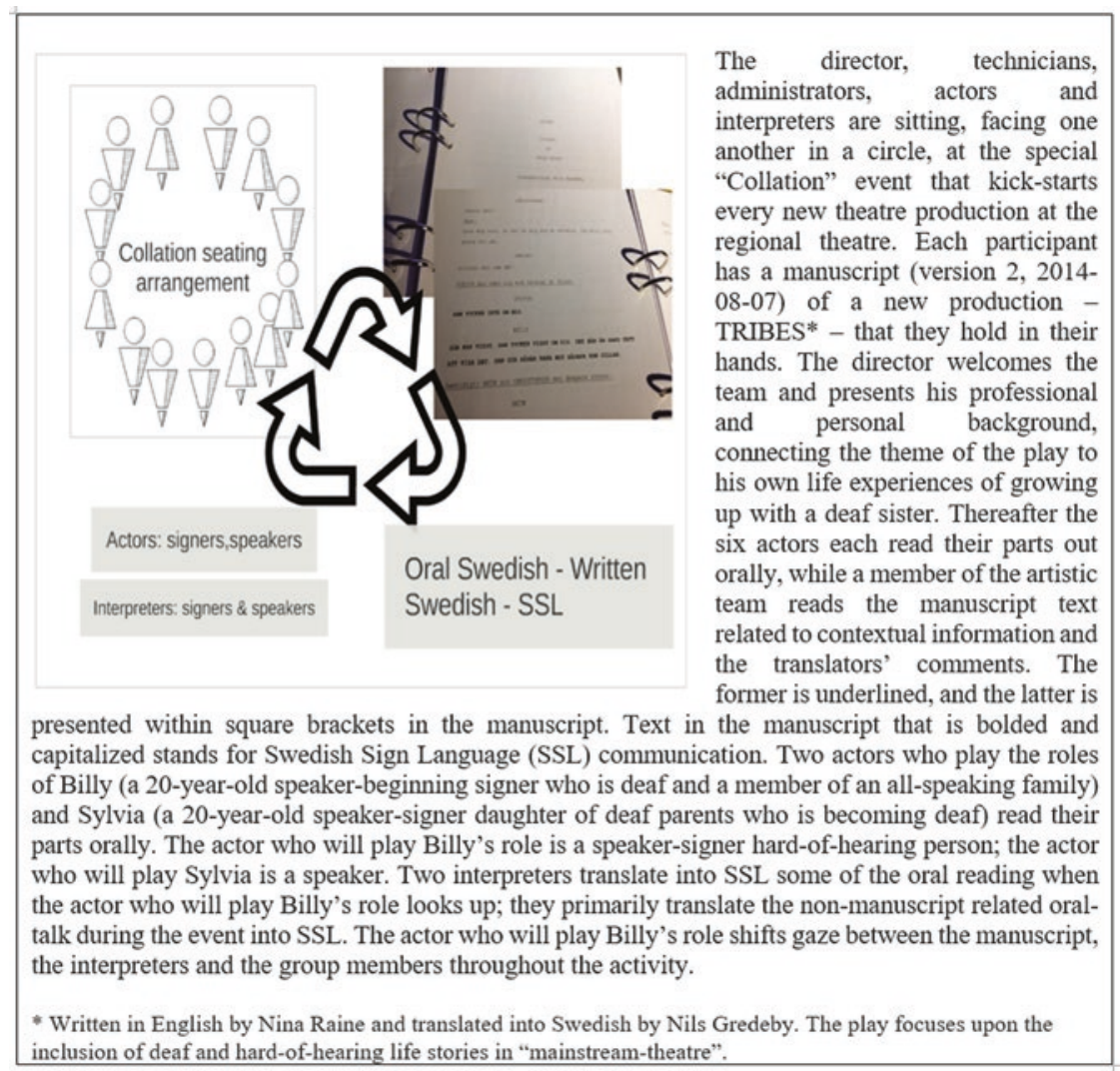

Fig. 12.5 Chained oral-written-signed embodied communication at a kick-start event of a theatre production (Project DS) 
where the participants "visual-orientation" ${ }^{2}$ necessitates camera presence and visual access by the participants as well as the researcher. This creates issues with writing fieldnotes since eyes on the notes being created mean that eyes on the actions that are transpiring in the field cannot be engaged with.

Resources from oral-written-signed named language-varieties and modalities are deployed in a complex medley when participants in a collation activity orally read-aloud written role parts and information, including comments, from a manuscript, and interpreters translate selected parts of the oral-talk into Swedish Sign Language (henceforth STS; previously also abbreviated to SSL) in the example presented in Fig. 12.5. Three participants in the social activity zoomed upon herethe actor who plays the central role of Billy, and two interpreters-are signers and speakers. If one focuses an audiological scale, this actor is hard-of-hearing and the interpreters are hearing. The circular seating arrangement where participants face one another is also a dimension of visual-orientation. Such use of space potentially enables access to embodied communicative resources. Having access to such social action through video-recorded data is of utmost importance if the nitty-gritty nature of peoples' actions are to be attended to. While the central written-text (the play by British author Nina Raine) used in the collation activity is re-cycled from British English to Swedish, access to data is curtailed in that the fieldwork is framed through the here and now.

The use of meaning-making resources from across named languagevarieties and modalities is chained (see further below). Even being inside a field (behind a camera) or focused on writing notes creates both affordances and restrictions regarding what the field is, where it is and when it is. This brings to the forefront issues regarding representational techniques that we have used so far, and that point towards specific layers of complexities that emerge in the analysis.

\footnotetext{
${ }^{8}$ In contrast with visual communication, visually-oriented languaging acknowledges the complex use of resources across oral-written-signed modalities.
} 


\section{Where, What and When Is the Data? Issues of Data- Creation and Representations}

A key theme regarding the handling of communication in the research enterprise itself relates to the nature of communication across time and space. Going beyond participants' and institutions' concrete accounts of their communication and deployment of different language-varieties and modalities, the issues and challenges related to emically studying languaging, learning and identity positions have been salient dimensions of the analysis in each of the projects we draw upon here. Salient for our argument is that each one of us has experiences of using the named language-varieties-oral, written and/or signed - that are deployed by the members of settings in the five projects. In other words, an interest in participants' use of particular named language-varieties and modalities comprises one aspect of our research interest here. The next two sub-sections focus upon the complexities of deployment of named language-varieties and modalities in participants' everyday lives and in textual spaces. Separating languagevarieties from modalities deployed in the mundane everyday life of human beings is done here merely for heuristic purposes; these are not separate.

\section{(Im)mobility Across Modalities}

The challenges faced by scholars working with data where one or more than one named language-modality or variety is deployed are, as we have highlighted above, numerous. For the most part, these get ironed out in a hegemonic sweep where oral (monolingual) talk is centre-staged. As for any researcher with similar interests, we have faced challenges vis-à-vis representing written and/or oral communication both in datasets from classroom settings and from virtual worlds. For instance, in the analogue datasets from project GTGS from the 1990s, we were focused to abandon the presentation of named language-varieties and modalities in any conventionalized manner since the participants did not, in the meaningmaking enterprise of their daily social practices, adhere to such 
conventions (Bagga-Gupta, 1995, 2012). These issues have continued to attract our attention in the twenty-first century.

From an epistemological perspective, action-oriented concepts give visibility to dimensions of human communicative social practices. Chaining constitutes one such concept. Drawing upon meaning-making in languaging, the term highlights equivalencies between linguistic resources and across modalities. In our previous studies from the projects, chaining has emerged as an emic dimension of multilingual-multimodal settings across scales: local-chaining (see Figs. 12.4, 12.5, 12.8, 12.9, $12.11,12.12,12.13$, and 12.14), event or activity chaining (see Figs. 12.6, 12.7, and 12.10) and simultaneous/synchronized chaining (cf. BaggaGupta, 1999/2000, 2002; Hansen, 2005). Going beyond the oral language and monolingual biases, the analytical-descriptive use of the concept chaining allows for highlighting the interconnectedness of both local phenomena (in terms of oral, written, signed and other semiotic resources) and trajectories of human interaction across time and space (see also section "Where, What and When Is the Field? Boundary Framings Across Physical-Virtual Spaces").

Analytically, chaining provides us with a fruitful way in which toboth within and across the five very different projects-illuminate the interconnectedness of oral, written and other semiotic resources in human communication (both online and offline) — rather than emphasize the separate nature of, for example, different named languagevarieties and/or modalities. Furthermore, analyses across the projects (see, e.g., project DIMUL, for example, Gynne \& Bagga-Gupta, 2013, 2015) emphasizes (1) the importance of methodologically bringing together various datasets in analyses, (2) analytically highlighting the interplay of oral, written and other modalities in both micro-interactional and meso scale analyses of languaging and (3) engaging in these endeavours across time and space. Such dimensions can be seen in Fig. 12.6a, $\mathrm{b}$, and $\mathrm{c}$ that illustrates a learning activity, in which two boys in a project DIMUL classroom were working on a project-based task within the school subject of Geography. The chosen project topic was "China" and it was framed by both oral and written pedagogical instructions in the named language-varieties Finnish and Swedish in a manner where the two were also assigned to different modalities. This means that the teacher presented 
oral instructions primarily in Finnish, while the instruction sheet handed out to students (Fig. 12.6a) was in both Finnish and Swedish. Such languaging reflects the practices and the formal policy of the school.

During their work on this specific classroom task, the two students in focus used a laptop and conducted searches on the Google search engine (Fig. 12.6b) with the intent of finding facts that would support their report writing (Fig. 12.6c). Such a work flow raises the issue of where the students are when they move beyond classroom spaces as well as our possibilities of accessing this type of data. The students' working process on this type of task also stretched from the physical classroom to home spaces and across the time-span of two weeks; such classroom work routines pose specific types of challenges for data-creation. The analyses of

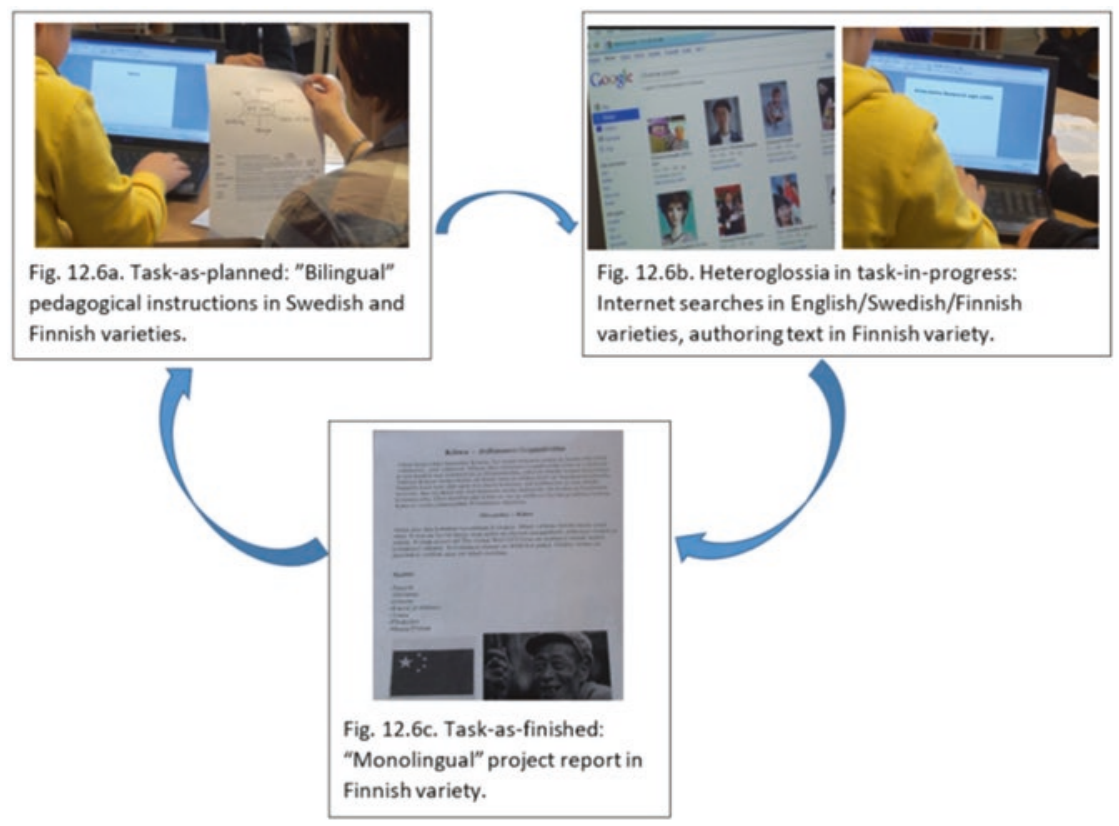

Fig. 12.6 Languaging in pedagogical instructions, working process and final project presentation (project DIMUL; see also Gynne \& Bagga-Gupta, 2015). (a) Task-as-planned: "Bilingual" pedagogical instructions in Swedish and Finnish varieties. (b) Heteroglossia in task-in-progress: Internet searches in English/Swedish/ Finnish varieties, authoring text in Finnish variety. (c) Task-as-finished: "Monolingual" project report in Finnish variety 
both this particular learning activity and the outcomes of other similar activities (see Gynne \& Bagga-Gupta, 2015) highlight not only chained and heteroglossic languaging but also people's activities in concert with tools across space and time. We faced similar challenges in project GTGS in the early 1990s where the activity-system of the NGO that formed the basis of fieldwork and data generation was itself dispersed across the mega-city of Bombay. ${ }^{9}$ This meant that we needed to follow the trajectories of participants across the city as well as between their private spaces (homes, for instance) and professional work places (Bagga-Gupta, 1995, 2012, 2014b).

Project DS datasets highlight a number of different types of chaining (as we have already seen through Fig. 12.5). Here we illustrate some of these through lessons in STS. These as well as lessons in social/natural science across the school years are often organized into theme units that are focused upon across a couple of school days. Furthermore, the use of different language-varieties and modalities in systematic and multilayered ways characterizes, as we saw earlier in the theatre collation activity, mundane languaging in these contexts. Figure 12.7 represents the routine organization of life, the participant constellations, the patterned flow of named language-varieties deployed and tools used during the analytically identified phases in one DS project context. ${ }^{10}$

The creation of a visually oriented video narrative enables collective analysis of a task during a whole class discussion phase of a STS lesson. The process of producing a visually oriented video-text, however, necessitates the creation of a text first on paper. In other words, pupils are required to (re)produce and (re)use a written text that circulates in classroom practices over time and across space during the course of the STS lesson-unit (Fig. 12.7):

- Pupils individually author a narrative in the main classroom and adults and/or other students comment upon this in the classroom.

\footnotetext{
${ }^{9}$ The city is now called Mumbai.

${ }^{10}$ See Bagga-Gupta (2002, 2004, 2014a, 2019a) for other examples of STS lessons from the projects from where data are drawn.
} 


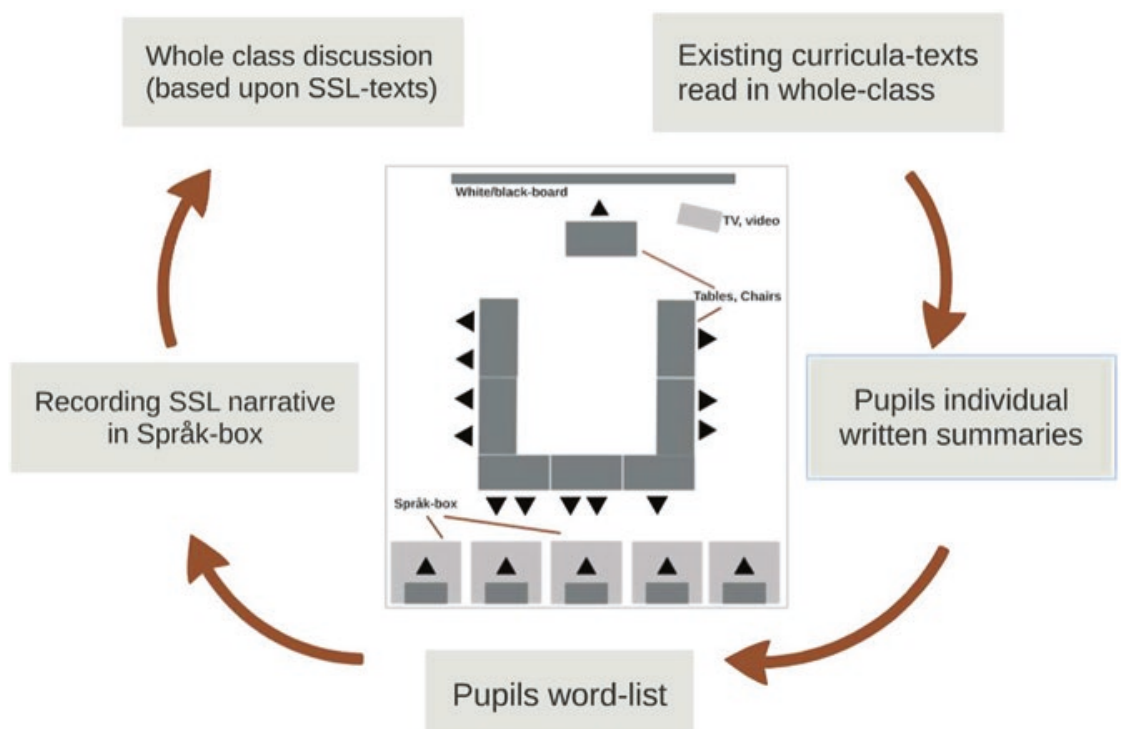

Fig. 12.7 Cyclic-chained activity of signer-writer pupils and teacher during STS lessons (project DS)

- Once the written text has been approved by an adult, the pupils proceed to individually create a list of keywords, also in the main classroom.

- The keyword list is used as a resource for producing a coherent visual narrative in the small technology infused spaces called Språk Boxes (Sw-En: Language Boxes). ${ }^{11}$

The teacher-led phases of the STS lesson-unit are interwoven with individual or small group work phases either in the named languagevarieties STS or Swedish or a complex mixed pattern where both are in concert. Such languaging over larger chunks of time constitutes "activitychaining" and "cyclic-chaining". ${ }^{12}$ STS usage dominates during specific phases, while the use of primarily written Swedish dominates during oth-

\footnotetext{
${ }^{11}$ See Bagga-Gupta $(2004,2014,2017,2019$ a) for more on these spaces.

${ }^{12}$ See Bagga-Gupta (1999/2000, 2002, 2004, 2010, 2012a), Hansen (2005), Hansen and BaggaGupta (2017), Gynne (2016, 2017) and Gynne and Bagga-Gupta $(2013,2017)$ for other examples of these types of chaining in both speaker-writer and speaker-writer-signer settings.
} 
ers; both modalities and varieties are intricately interwoven in large parts of the interactions during some. In addition to the chaining of the two named language-varieties STS and Swedish, there is a layering of different modalities here:

1. the visually oriented signing modality on-the-hands (mediated via tools like TV, video-player, whiteboard (WB) etc), including the composite signing resources of fingerspelling, mouthing etc);

2. the written modality in textual tools like books, papers, whiteboard etc.; and,

3. the oral modality on-the-mouth.

The analysis of the dispersed nature of languaging represented in Fig. 12.7 is also related to the data represented in Fig. 12.5, where languaging at the kick-off event of a theatre production involves the layered use of different named language-varieties and modalities. The oral and written varieties, Swedish and STS, including embodied linguistic resources (of fingerspelling and mouthing), are chained in patterned ways: at the micro-interactional level, at the meso-activity level, and furthermore, when oral-talk by a speaker is translated into STS by a signer. Such mundane chained languaging is, as we pointed out earlier, visually oriented (rather than being only "visual"). This means that access is framed through written-language, signed-communication, embodiment, and includes the use of oral-talk: here different tools, varieties and modalities are employed in patterned ways.

While an important part of the creation of data in the DS projects was that we created and had access to video-data even when we were present physically in the classrooms, getting access to areas where individual students were creating their video-narratives as well as accessing the analogue and digital word and video-texts was not always easy. Furthermore, handling datasets where languaging was either taking place entirely in cyberspace or across the virtual-physical divides raised its own issues. Starting with more simplified oral talk transcriptions, the addition of features of written texts in our transcripts enabled representing the complexity of languaging in more detail. Projects CINLE and DIMUL also highlight this issue. We have resorted to, for example, the use of screen 
shots of the chat tool used by participants inside our transcripts (Fig. 12.8; see also Messina Dahlberg \& Bagga-Gupta, 2014). Embedding screen shots in the transcript in the sequentiality of the interaction allows for representing a turn-at-talk, and goes beyond the oral language and the monolingual bias in contemporary reporting.

However, the chaining of different modalities is at times difficult to represent as separate turns, since participants use the chat tool as a parallel conversational floor. Using a table with different columns to represent a timeline, the oral talk and the written mode afforded by the chat tool allows for making visible this layer of complexity (Fig. 12.9). In addition, since the sequentiality of talk did not rely solely on the oral mode, it became necessary to create a transcription system that would account for the chaining that occurs across modes, time and space, including digital spaces (Fig. 12.9).

The arrows in Fig. 12.9 highlight that the student orients towards both the task as it is displayed on the WB and to offline material in the form

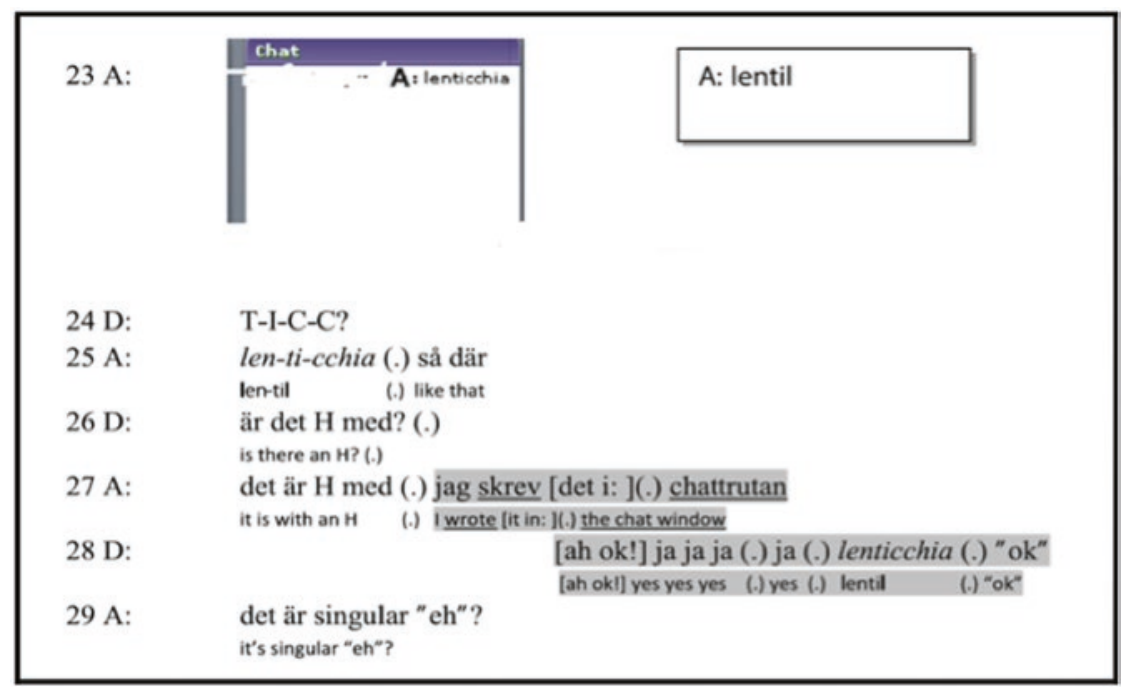

Fig. 12.8 Example of transcription system where screen shots are used (project CINLE; adapted from Messina Dahlberg \& Bagga-Gupta, 2014). Note on transcription conventions used in Fig. 12.8: Grey highlighted: participants' topicalization of the chat-tool content; T-I-C-C: orally spelled word 


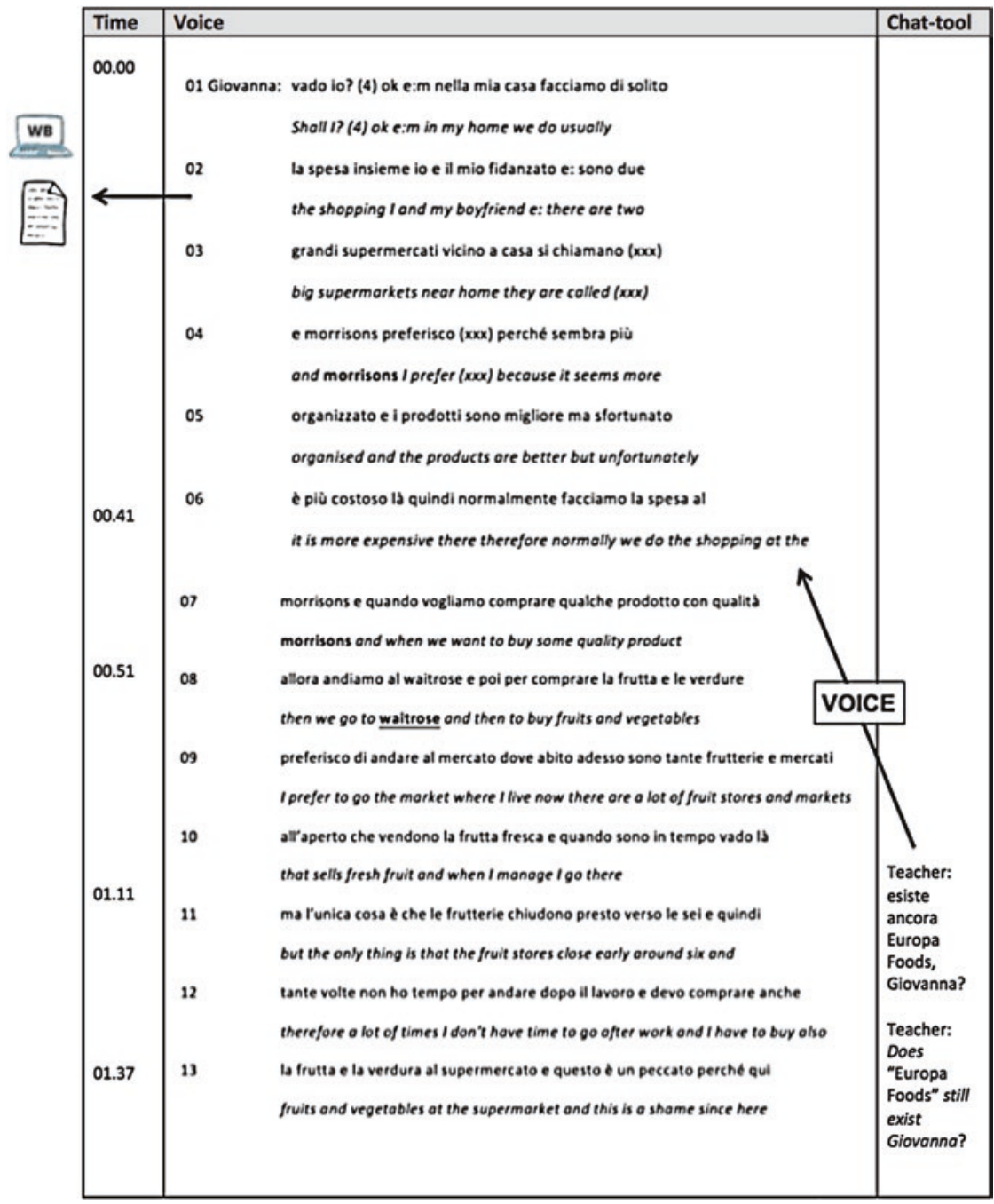

Fig. 12.9 Example of transcription that uses arrows to highlight chaining across modes and literacy practices, online and offline (project CINLE; adapted from Messina Dahlberg \& Bagga-Gupta, 2016)

of Giovanna's physical handwritten notes (Fig. 12.10). Thus, chaining as an analytical construct allows for visually representing and mapping the ways in which languaging is afforded (and constrained) by the set of semiotic resources that participants have access to and indeed deploy dur- 
ing any stretch of interaction. Such use of resources also has consequences for how participants orient towards one another in the oral mode; we the analysts thus need to engage with the fragmented character of languaging across digital-physical spaces by expanding the use and conventions of interactional analysis, including conversation analysis wherein oral talk has been traditionally privileged.

Figure 12.10 illustrates the chaining between the written texts inside the virtual classroom (online) and at one student's physical desk (offline) during the stretch of interaction illustrated in Fig. 12.9. A close analysis of Giovanna's offline notes allows us to follow and attend to the intricate chaining within digital languaging. In these notes, the student writes some sentences in Italian that the teacher has written in the chat tool inside the online environment: no, è che ci ho lavorato tanti anni fa (Italian: no, it is that I have been working there for several years; highlighted in Fig. 12.10). Illuminating the nature of people's languaging thus implies that data generation needs to be sensitive to both practices inside and outside digital spaces-even when the instructional activity takes place only in a virtual platform, as was the case in project CINLE.

The analytical focus here lies on chaining across time and space-that is, what takes place at the student's physical space in terms of the creation of notes as a task-oriented activity framed within the online language

Online: languaging in the virtual classroom

Offline: languaging at a student's desk

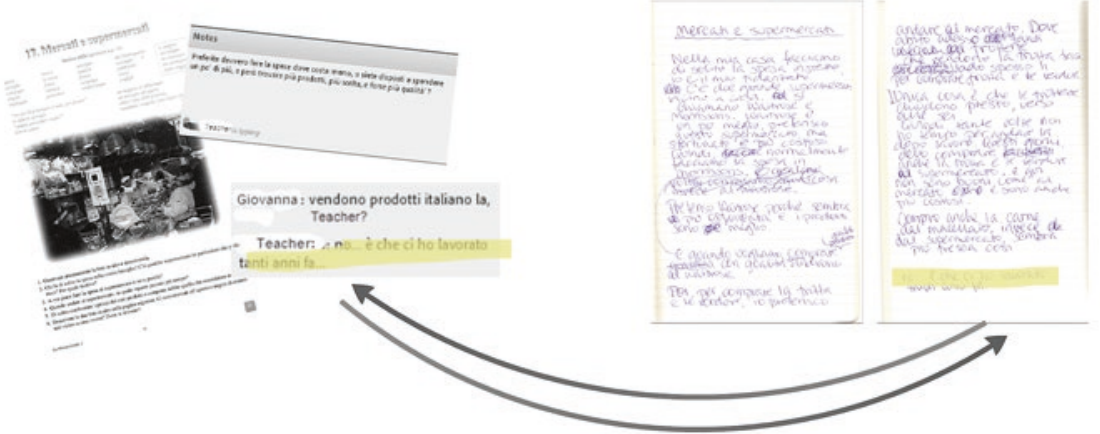

Fig. 12.10 Literacy practices and chaining at the borderlands of digital/physical or online/offline spaces (project CINLE; adapted from Messina Dahlberg \& BaggaGupta, 2016) 
course. Giovanna's handwritten notes are visible on the right side of Fig. 12.10. The analysis of the synchronous meeting in Adobe Connect shows that Giovanna uses the written notes in lieu of a manuscript to perform her contributions in the virtual classroom: the oral contribution is identical to the written text in her notes. Giovanna's performance of her notes gets interrupted when the teacher asks a question in the chat tool (Fig. 12.9). Accessing such offline data has, however, not been an easy task for us as ethnographers and analysts. This draws attention to a research and fieldwork design that leaves many doors open in terms of what data is possible to generate. In this case, the written notes have been elicited only after the virtual data-creation process had started and when particular patterns of participation had emerged in the initial analysis: for instance, when we suspected that students were reading aloud specific scripts, which we could-based upon offline data-show they were (Messina Dahlberg \& Bagga-Gupta, 2016).

\section{(Im)mobility Across Language-Varieties}

An issue we faced during some of our early projects (in the 1990s) concerned what transcription system to use for the different named languagevarieties and modalities in our data: for instance, the written word in addition to the spoken (project GTGS) or the written word in addition to the signed and where oral resources were present (project DS). As pointed out above, people's mobilities and use of space was significant in these projects too. Given our interests of making visible different dimensions of everyday interaction (see also Flewitt, Hampel, Hauck \& Lancaster, 2009), the need arose for going beyond available transcription

Due to trains running late on the WESTERN LINE the CENTRE was opened only at 9.30 a.m. One COMMUNITY woman was beaten up by her drunk husband at night. She has been treated at the CENTRE. Shanti made a COMMUNITY VISIT to talk to the men during their lunch break. The woman's husband was not there, but Shanti spoke to the people in the neighbouring jhuggies. The DELIVERY VAN arrived with the monthly STOCK.

Everything ordered has arrived.

Fig. 12.11 Adult Hindi-ENGLISH written communication (project GTGS, reproduced from Bagga-Gupta, 1995, p. 125). Note on transcription conventions used in Fig. 12.11: Abcd efi: Hindi words in the text; $A B C K$ EFl: English loan words in the text; $A b c d$ : specific Hindi words retained in the text (eg. Jhuggies) 
conventions. Projects GTGS and DS are particularly illustrative in this sense, not least since they emerged in the 1990s. Figure 12.11 represents a written diary entry (project GTGS, 1990s dataset) and the analytical stance we took to present it in a 1995 publication.

The issue of representing multiple named language-varieties that have different scripts and where the participants used separate scripts for separate language-varieties at times and used one script for different languagevarieties at other times or transliterated the language-varieties in an ad hoc manner called for careful consideration regarding how to represent both oral language and written language examples from the dataset. Figure 12.12 explicates our attempts to tweeze out the issues we faced more than two decades ago.

Analysing project GTGS datasets from 2012 to 2014 is enabled by a different set of concerns but significantly also by the availability of digitalized resources. Reporting upon discussions about gendered violence in public spaces in the mega cities of New Delhi (Dilli), Mumbai (Bambai) and Poona (Pune), one of our previous studies presented transcripts using the Latin script even when the far majority of the oral talk transpired in

1. Hindi and Marathi oral and written discourse is represented by the use of a smaller font (in contrast to referenced quotes from other texts).

2. Capitalised italics represents "English loan words in their Hindi and Marathi oral discourse, and English loan words written in the Devanagari script in their written texts" (Bagga-Gupta 1995: xv).

3. Specific Hindi terms are presented in italicised form and their inclusion is qualified in the following terms: "firstly, many of them have long translations...; secondly, such terms usually carry a composite of meanings...; thirdly, many of these terms... are regularly used in English texts and in some sense are on the way to being (if they have not already been) incorporated into the English language vocabulary" (Bagga-Gupta 1995: xv).

4. The convention of using the South Asian Roman font that is commonly used in the literature to transliterate Indian languages like Hindi and Marathi into the Latin script is only sparingly used in the reporting. BaggaGupta offers the following arguments for this choice: "I have consciously chosen not to use this system in my own text, since texts that are produced and used at the Mobile Crèches use a more everyday phonetically based method to transliterate these words... In addition, I am not aware of any font system that could be used to convey the fact that English loan words were being transliterated into the Devanagari script. And neither could one make clear the fact that sometimes two to three languages were being used within the same textual practice. In fact, the use of the South Asian Roman font would undermine the dynamic nature of the written and oral discourse that exists within the different arenas at the Mobile Crèches" (Bagga-Gupta 1995: xv).

Fig. 12.12 Analysts' account of attending to multilayered oral-written complexity in academic reporting (project GTGS; reproduced from Bagga-Gupta, 1995) 
1.01: film से समडज आता है के हमारे जो शहर है तो किस तेरे से ओउरते के प्रति hostile हो चुके है we can understand from the film how cities have become hostile for women

105: तो ये सिर्फ़ दिल्ली के कहानी नहीं हे (.) बम्बई में एहि है पुणे में एहि है this is not the case with dilli (.) in bambai too in pune too

109: बम्बई में जहा में बड़ी पढ़ी हुए हूँ bambai where ever $\mathrm{i}$ have grown up and studied

1.12: और जहा खबि कोई रोक धोक नहीं ता की घर इतने बझे तक आना है and where there were no restrictions about what time one had to return home

1.16: कवकी बम्बई मई एक सुरक्षा थी अवुरातीं के लिए because there was safety for women in bambai

1.20: पर हम देख राजे है की बम्बई में भी वो सुरक्षा काम होइते जा रही है but we are seeing that even in bambai this safety is becoming less

Fig. 12.13 Chaining and meaning-making-representation of original oral talk and translated oral talk (project GTGS, 2012 dataset). Note on transcription conventions used in Fig. 12.13: Oral talk in bambaiya-hindi: presented in Devanagri script; Oral talk in English: presented in Latin script underlined

Bambaiya-Hindi (see Bagga-Gupta, 2014b). We represent a slice of a previously discussed transcript now using digital resources in Fig. 12.13.

The translation of this stretch of oral talk can be understood as being un-problematic at one level since almost all of it can be assigned to the language-variety Bambaiya-Hindi. However, given that the vernacular is recognized as a dialect of Hindi, such transcriptions build upon phonetic renditions that are non-standardized, risking being riddled with issues. Furthermore, we have assigned two lexical items to the named language-variety English in Fig. 12.13. While the word "hostile" would not be accepted as a part of any dialect of Hindi (by any stretch of the imagination), the same cannot be said of the item "film". Given the fact that Mumbai/Bombay is the seat of Bollywood and is also called "filmcity", the usage of this word crosses linguistic boundaries. This complicates the fact that the meaning-making represented in line 1.01 includes the chaining of resources from (at least) two linguistic systems in the oral talk. 


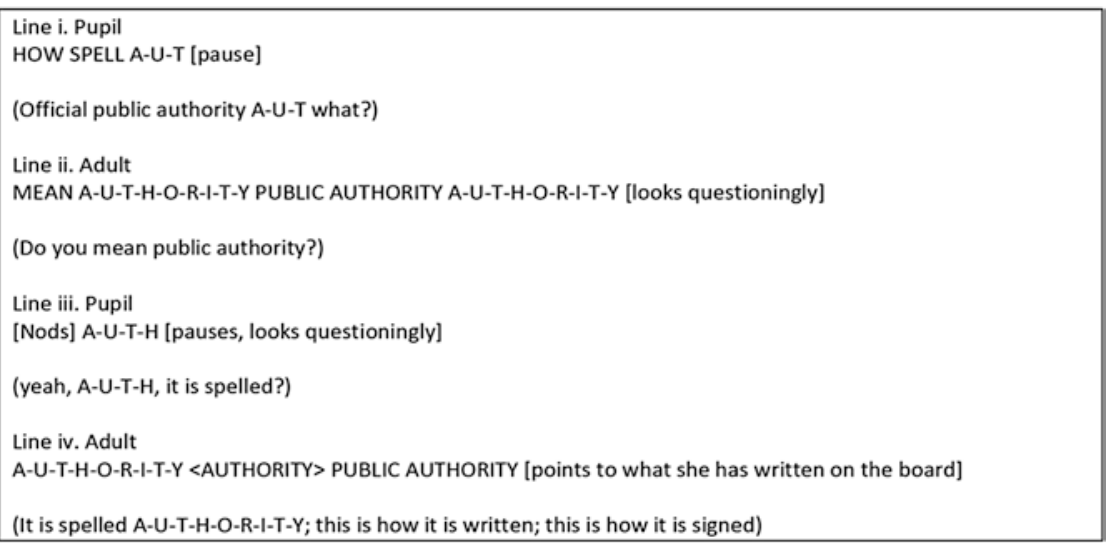

Fig. 12.14 Chaining and meaning-making-adult-teenagers STS-Swedish communication (project DS; adapted from Bagga-Gupta, 2004, pp. 193-194)

Similar issues vis-à-vis meaning-making are at stake in the context of the DS projects as we have already seen above. Participants' use of resources from the named language-varieties Swedish and STS involve focusing upon a language-variety on-the-mouth (oral-talk), on-the-paper (written communication) and on-the-hand (signed communication). Furthermore, linguistic resources like fingerspelling and mouthing - significant dimensions of visually oriented languaging — needed to be made salient in the transcriptions. Finally, use of space and embodiment (pointing, underlining, sitting face-to-face etc.) constitutes meaningful dimensions that need to be highlighted in the reporting. Representing the visually-oriented languaging where a signed modality interacts with written and oral resources of a language like Swedish is built upon textual resources enabled by two-dimensional reporting (Fig. 12.14).

Spelling out the alphabets on-the-hand is similar to sounding-out alphabets in oral talk (see Figs. 12.8 and 12.14). Such fingerspelling is a composite dimension of languaging that is visually oriented. As we have argued for analytically, and illustrated here empirically, being able to tweeze out the rich or complex nature of languaging necessitates that the analysts are experienced users of the language-varieties deployed in the communities or affinity spaces that they are interested in. Using interpreters, for instance, would not allow for such a close scrutiny of the 
meaning-making potentials that participants are engaged in. Such experiential baggage together with creativity and reflexivity constitutes the corner stones of research as action.

\section{Researchers' Positioning Repertoires in and Across Fieldwork Phases: Individual and Joint Enterprises}

The last overarching challenge that we focus upon in this chapter relates to the need for explicitly illustrating and discussing the role of the researcher during as well as beyond fieldwork phases. Focusing upon reflexivity, the choices and challenges that have emerged and that we continue to face during fieldwork (e.g. in projects GTGS and PAL), analysis and writing phases (both during collaborative and during individual writing) are centre-staged here.

Ethnographer's reflexive work is essential during as well as beyond fieldwork phases. Entering social settings as a (participant-)observer routinely entails producing written accounts of people's practices in those settings. Thus, a common (n)ethnographically inclined procedure in all our projects was that of writing fieldnotes, a process that consists of several phases, in which we as researchers went from taking headnotes or jotting, to constructing relatively coherent sequences of action and evocations of scenes and characters we had followed (Emerson, Fretz, \& Shaw, 1995, p. 51).

Figure 12.15 provides an example of the processes involved in datacreation during which an analyst moves from observations and fieldnotes to the preparation of transcripts and excerpts and further on to the presentation of data at data-sessions and other research activities like seminars and conferences. In project CINLE, data was created by recording the online synchronous meetings of an Italian for beginners' course inside the videoconferencing platform Adobe Connect (see Fig. 12.3). This type of work is commonly understood in terms of "adopting an ethnographic perspective" (Androutsopoulos, 2008, p. 15) or understanding (n)ethnography "as a method, not an epistemology" (Androutsopoulos, 2008, p. 2). This follows from the fact that digital technology enables creating a data corpus that was not possible in pre- 


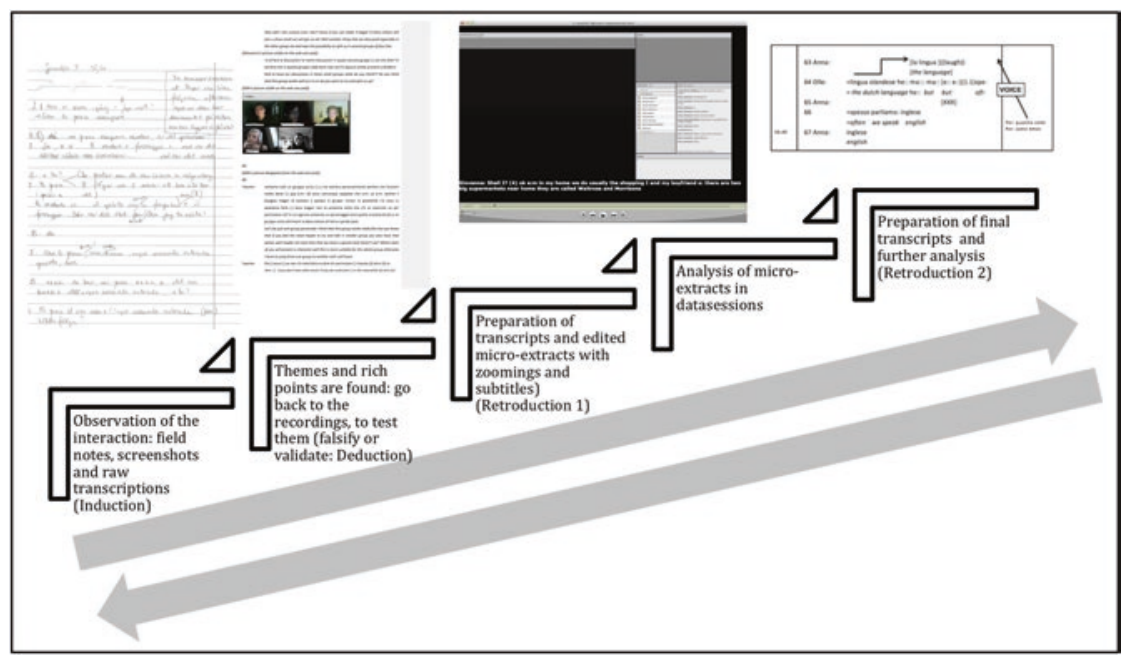

Fig. 12.15 The reiterative processes of data-creation and analysis (project CINLE; adapted from Messina Dahlberg, 2015)

digital times where observations were recorded by means of paper and pencil, or an analogue video-recorder or tape-recorder.

In addition, the organization of knowledge circulation in academia, for instance, takes place through the production of relatively short journal articles that are a challenge when it comes to ethnographic writing. This means that the limited writing spaces of scientific journals necessitate compressing the rich and complex accounts of social practices. While some journals create possibilities for the inclusion of data (including video-data) in online spaces, ethical issues often curtail analysts' possibilities to do so. In other words, there is an increasing tension between what is known about society and constraints related to "holistic" representations in the scholarship: "what is holistic representation? What is holism once the line between the local worlds of subjects and the global world of systems become radically blurred?" (Marcus, 1986, p. 171).

Pink, drawing from Okely (1996), refers to the concept of retrospective fieldwork, that is, how the researcher's personal experiences are used in the creation of ethnographic knowledge which may, later on, "become part of 
a piece of professional work" (Pink, 2007, p. 34). Thus, for instance, in project CINLE a relevant point of departure was our (i.e. Messina Dahlberg's) previous experience as a teacher in online language courses at the same institution where fieldwork was conducted. This means that retrospective fieldwork is a mixture of the researcher's own experiences as a former professional in the field, but also, and very importantly, it refers to the possibility enabled by the digital format of recordings of the virtual classroom to go back to the field, with the intent of observing the phenomena closely from the same point of view as if we were there, in the specific moment in time when the actions unfolded. Our going back to the recordings is (in this and other projects) also, in this sense, a re-enactment of the educational sessions, from the perspective of the other participants in the encounter. Here the position of the researcher necessitates leaving and taking on a different role in the field of engagement, that is, leave the role of a professional and take on the role of an analytical scholar. This process is also facilitated by the collaborative nature of data-sessions and co-authorship.

Another example of the many positions that a researcher may enter during different fieldwork phases can be illustrated from project DIMUL (Fig. 12.16). Being an ethnographically oriented researcher in the physical classroom entails positioning oneself both physically and socially in relation to the field and the people in it. In the classroom, the physical position of the researcher consists, more often than not, of being a (participant-)observer, sitting at the back of the classroom, jotting down fieldnotes or manoeuvring a video camera or other equipment. This is a position which entails different kinds of social interactions and moment by moment shifting roles; in DIMUL (as well as in the GTGS project), these included being "borrowed" as an assistant teacher or being friendly with someone during class work and/or recess or taking on consultative tasks. Being in the virtual field allows for other kinds of social positionings, which in many ways coincide with the identity position the researcher is ascribed to in physical spaces like classrooms. In project DIMUL, a researcher profile was created on Facebook solely for the purposes of fieldwork (Fig. 12.16 bottom middle). This profile allowed us to become (participant-)observers, whereby we could follow members languaging and identity work across time and space. Furthermore, Fig. 12.16 illustrates the researcher in DIMUL being positioned by a 


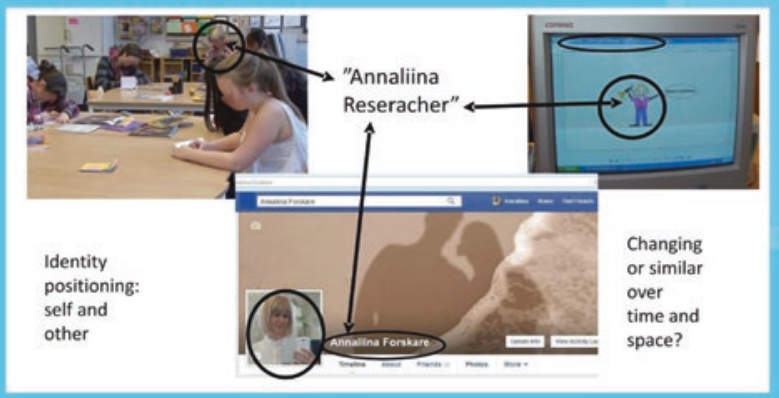

Fig. 12.16 The many positions of a researcher. Researcher identity-positions in project DIMUL

few participants, in a drawing, created on a computer in the physical classroom. Here, the researcher is given her "Facebook alias" name (which is not her real surname). The students inscribe her in a specific position, by illustrating her with a video camera in her hand-a position in which she appears to be engaged in the very "doing of research".

Positioning of researchers across fieldwork in digital and physical spaces includes being there, but at the same time also here. The researcher's professional persona needs to be understood in terms of a: "recalibrating practice of positioning in terms of the ethnographer's shifting affinities for, affiliation with as well as alienation from, those with whom he or she interacts at different sites [this] constitutes a distinctly different sense of 'doing research"' (Marcus, 1995, p. 113).

A qualitative research(er) perspective calls upon scholars to shift between being outsiders and insiders. Such shifting positionalities necessitate that scholars remain open to unexpected developments. In contrast, scholars within a positivistic tradition are specifically expected to maintain an unbiased vision — and remain outsiders_-in relation to their research objects. Denzin and Lincoln refer to this as the "gold standard" of educational research, where evidence-based methods were seen as the "good 
way" of conducting research (Denzin \& Lincoln, 2000, p. 1). Furthermore, such closeness and distancing of the researcher from his/her subjects is in line with the historical and theoretical backgrounds of anthropology and ethnography as colonial endeavours. Figure 12.17 illustrates some of our positionalities inside physical and digital sites of engagement.

The methods used in ethnography create a window into the world through the use of a range of practices and representations which themselves change that world (Denzin \& Lincoln, 2000). Thus, looking at research subjects/participants is always looking at the Other through the epistemological lenses that derive from the use of language, gender, social class, ethnicity and other fluid positionalities (ibid.). In this sense, the researcher becomes a multicultural subject, because "we no longer have the option of deferring the decolonization project" (ibid., p. 11). This means, we argue, that researchers need to acknowledge the complexity of their own lived experiences as well as the vantage points they bring with them to their analysis and reporting, providing layered understandings of different processes that are in focus.

By attending to the complex layered dimensions of languaging in both mundane everyday life (i.e. data) and in the languaging within research processes themselves (data at a meta-level), we engage with reflexivity by attempting to illustrate and make visible the mundane nature of social practices across different projects where we have generated data and have participated in the analysis and reporting enterprise. A significant caveat here is that our ethnographical journeys across time and space need to be
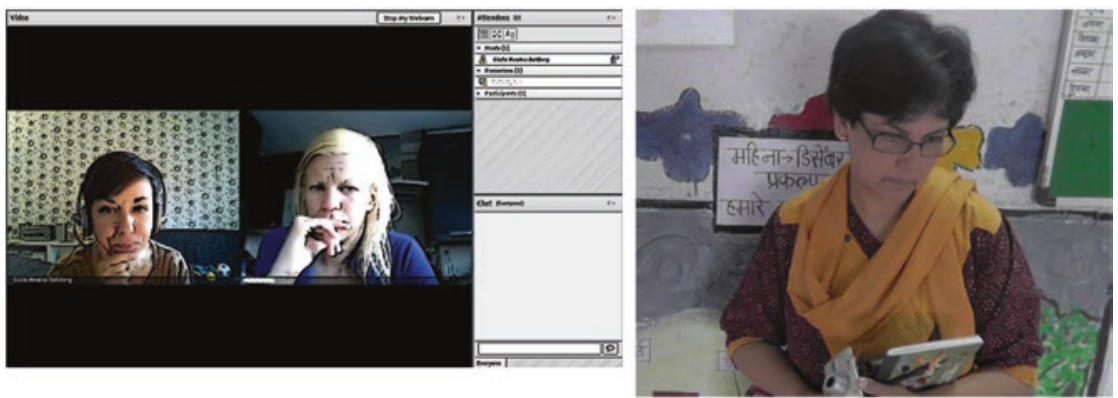

Fig. 12.17 Being there, but also here. Doing research at borderlands (projects CINLE and GTGS) 
seen in terms of representations in scholarly writings from diverse angles, none of which will ever succeed in (re)creating the ethos and complexity of the world "out there" (Clifford \& Marcus, 1986). Representations are just "representational" simplified snapshots of everyday life. We, however, suggest that such limitations can be partially bridged in the collaborative and creative processes of doing research across the boundaries of academic domains, named language-varieties and modalities, geopolitical spaces, projects etc. (Fig. 12.18).

A reflexive collaborative research enterprise across time and space, including physical and virtual spaces, as illustrated in Fig. 12.18, is essential for the viewings and voicings of the common dimensions of human
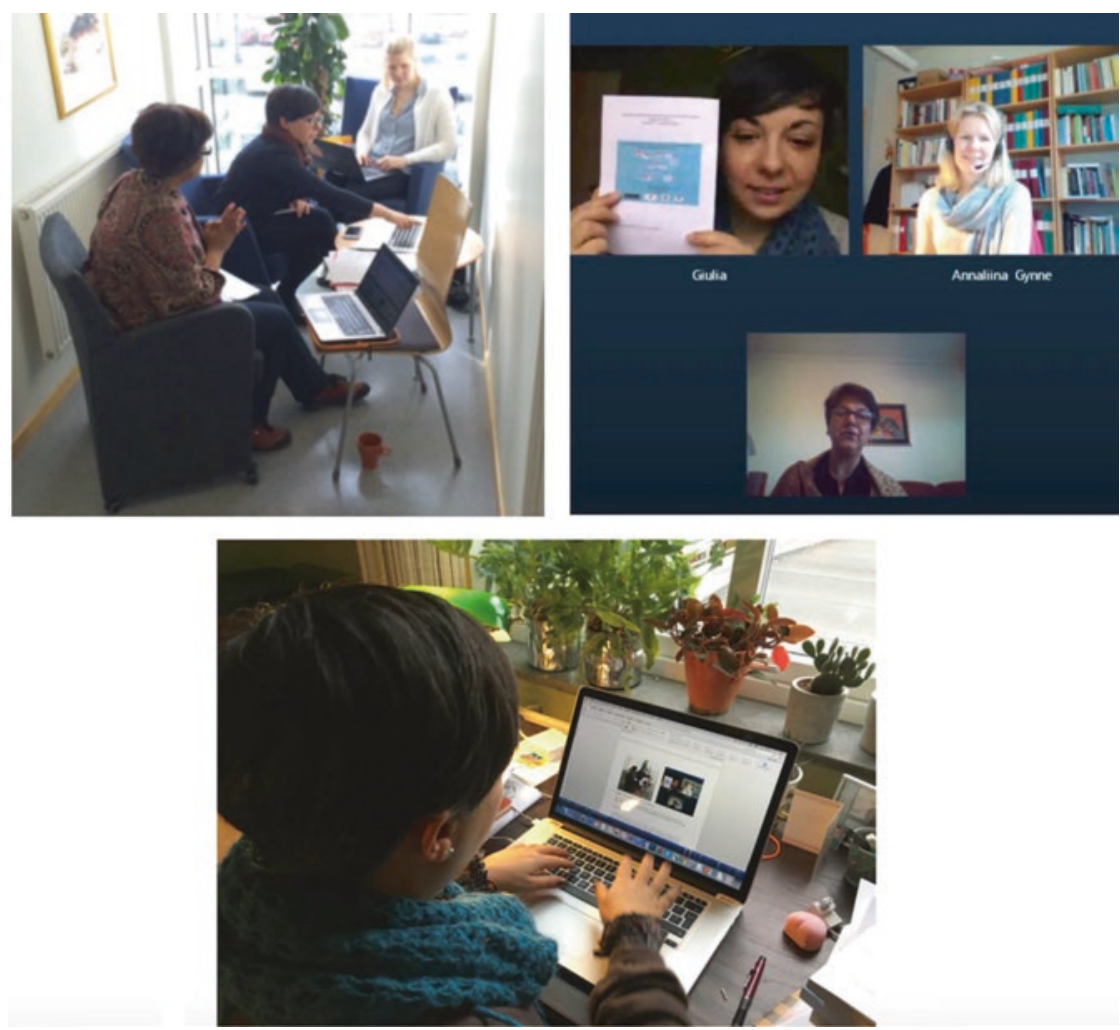

Fig. 12.18 Doing research in collaboration across time and space: IRL, online, while contributing individually by writing at one's desk 
action and the more specific characteristics related to a specific context. It is such a point of departure that is relevant for critical discussions of discipline-related ontologies and traditions. Reflexivity, in other words, implies attending to such limitations and accounting for the ways in which analysis and representations are inextricably bound to the researchers' viewings and voicings, in terms of the researchers' analytical toolkits and the material artefacts that are used during the process of data-creation, analysis and reporting. Reflexivity in the research process opens for the acknowledgement that we (researchers) are always in a process of becoming, recognizing the limitations of research, including our own prior experiences/ limitations, and furthermore, recognizing the fluidity and processual nature of the phenomena that we are studying (Cerwonka \& Malkki, 2007).

The analytical discussions we have raised in this section are also associated with a creative, ethically responsible and never-ending journey across a scholar's lifespan, through his/her experiences with other scholars within projects, research fields, issues and includes the areas of interest that the scholar has navigated. Reflexivity, furthermore, helps us position ourselves in relation to research in terms of "a multifaceted, complex and ongoing dialogical process that is continually evolving" (Byrd Clark \& Dervin, 2014, p. 2). Engaging with reflexivity thus enables us-scholars-to potentially become aware of the ways in which representations inflect and shape our own viewings, which in turn is shaped by our epistemological lenses as well as our experiences as human beings. Thus, a reflexive aperture is far from neutral; it is — at best-reflexive in its endeavour to critically engage with its own analytically framed assumptions.

\section{Reflexivity and Creativity: "Unboxing" the Research Process}

The study presented in this chapter explicitly illustrates and discusses the role of the researcher during as well as beyond fieldwork phases in the research enterprise. Focusing upon reflexivity, the choices and challenges that emerge and that we continue to face during fieldwork (in current projects), analysis and writing phases (both during collaborative and 
individual authorship) have been touched upon implicitly in the previous sections. They are centre-staged in this final section.

Our analyses touch upon key issues of being a researcher situated in the human sciences and the doing of research within the human sciences in the twenty-first century. Affordances of digital technology enable, for instance, the doing of research across spaces: the researcher can stay "at home" and access participants through online engagement. Juxtaposing projects and datasets, as we have done in this chapter, opens up for alternative understandings of the complexity of research methods as practice at a range of levels:

- first, in relation to issues of fieldwork and the imagined boundaries therein, and the complexities that arise in the digital age where access to the field is potentially only one-click or touch away;

- second, in relation to how we represent the (im)mobility of a digital field, including that of the researchers; and,

- finally, in relation to reflexivity in research and in how language, space and the very nature of human interaction defies being framed in the same analytical terms as when research was conducted with tape recorders and video recording equipment that could only be stored in car vans and boxes, rather than in the palms of our hands.

Ethnographic fieldwork, methods and data need to, as we have illustrated through the display of data and analysis, be analytically framed in terms of where, when and what is the field and data, including the researcher's positionality in and across different fields of enquiry. Going beyond participants and institutions' concrete accounts constitutes an important first step that allows for emically studying social practices, including languaging across projects (Back, 2015) as well as across physical-virtual learning sites. Employing a reflexive stance that is maintained across different phases of a research project is another key dimension that scholars engaged in (n)ethnographies face. Our point is that while this has been the case during analogue times, it is more so in the digital lives that ethnographers attempt to illuminate currently.

The collaborative and reflexive nature that is strived for within the five projects, the studies conducted within them, and the empirical 
nature of the work highlighted in this chapter, illustrates the importance of paying attention to different scales from an emic stance. This includes making visible participants' everyday concerns and behaviours. The chained and intertwined nature of languaging across settings that our work has identified highlights a common feature that points to the linguistic heterogeneity in the meaning-making enterprise of human communication (across the projects and datasets). This highlights the fluidity and hybridity of communication as well as of semiotic resources and repertoires: participants draw upon different means in order to make sense of the interaction going on here (their physical spaces), including there, if they are situated in shared online spaces simultaneously (see also Liddicoat, 2011).

The datasets that we have presented in this chapter highlight specific issues that have arisen for us as scholars across time. Physical spaces continue to be significant despite newer possibilities that digitalization enables. For instance, we as ethnographers (at best) have only a partial view of the different physical spaces where students are located while they are studying Italian in a course that is offered online. These students share the digitally mediated spaces of the virtual classroom, but also a range of materials that frame their choices of what to talk about in the oral and written modalities. Access to such local resources is completely curtailed - for us, the researcherseven though we have complete access to the specific virtual site of engagement. Students orient towards the course materials using mediating tools that are not transparent to the participants or for us analysts. Such analysis across micro-meso scales that encompass physical-virtual learning sites potentially (1) enables meeting challenges related to research methodological practices and (2) contributes to pedagogical insights. The latter, for instance, has consequences in the language and learning sciences where keeping named languagevarieties and modalities apart in instruction has long been the norm in global-North contexts like Sweden and where reporting of research reinforces the boundaries between named language codes and modalities. What (n)ethnography affords educational research today (focusing on human meaning-making) is the ability to map individuals' digital 
contributions to locate the movement of information and ideas across time and space. We argue that such a stance is key if we are to contribute from an emic, that is, participants' perspective. Such possibilities enable the creation of datasets that can be very large, encompassing a wide range of spaces and activities. However, scholars can only (re) create such shared spaces in the ethnographic processes of data-creation, representation and reporting.

Attending to the fallacy of thinking in terms of fieldwork in static geopolitical-linguistic spaces and communities, the work we have presented in this chapter also highlights the need to focus on the distributed-situated and the discursive-technological constitution of participants' worlds; that is, humans-in-concert-with-tools (BaggaGupta, 2014a). Furthermore, data-creation and analysis are strictly connected processes in our research endeavours (and in line with an ethnographic, open-ended approach) where the issue of representation is crucial for making visible the complexities of (1) communicative processes across time and space and (2) our own processes of datacreation and analysis. This is illustrated in different ways in our examples and in our attempts at creating alternative representational techniques that attend to the (im)mobility of people, utterances, named language-varieties and modalities. Moreover, what the very different projects we have included in this chapter share is an underlying ambition of (re)creating (analytical) boundaries, that are shaped by research questions and endeavours, rather than by policy or/and ideology and normative stances.

Using a range of representational techniques constitutes yet another way in which scholars (can potentially) operationalize a reflexive stance. The data analyses we have re-presented and pointed to in this chapter illustrate the ways in which an analysis across scales and modalities can be holistically approached. The analytical snapshots presented in this study illustrate the ways in which knowledge is distributed across sites and boundaries. This is relevant in relation to a recent line of thought concerning a mobility-turn in educational research (Leandri \& Neumann, 2014). This turn encompasses alternative ways of (re)presenting the performativity of learning as economically, symbolically, materially pro- 
duced and reproduced by looking "in the middle of things" as well as their boundaries, with the aim of shedding light on "the material conditions of the circulation of people, things, objects and ideas" (Leandri \& Neumann, 2014, p. 2). Recognizing that following people's learning trajectories constitutes a complex endeavour, we argue that we as scholars need to pay critical attention to methodologies and epistemologies if we are to help ourselves understand the fluidity of such trajectories. Such a stance also (at least potentially) enables methodological integration and theoretical discussions to "unbox" the research process, making it more transparent for the analysts, the practitioners and, ultimately, the participants. 
12 Handling Languaging During Empirical Research...

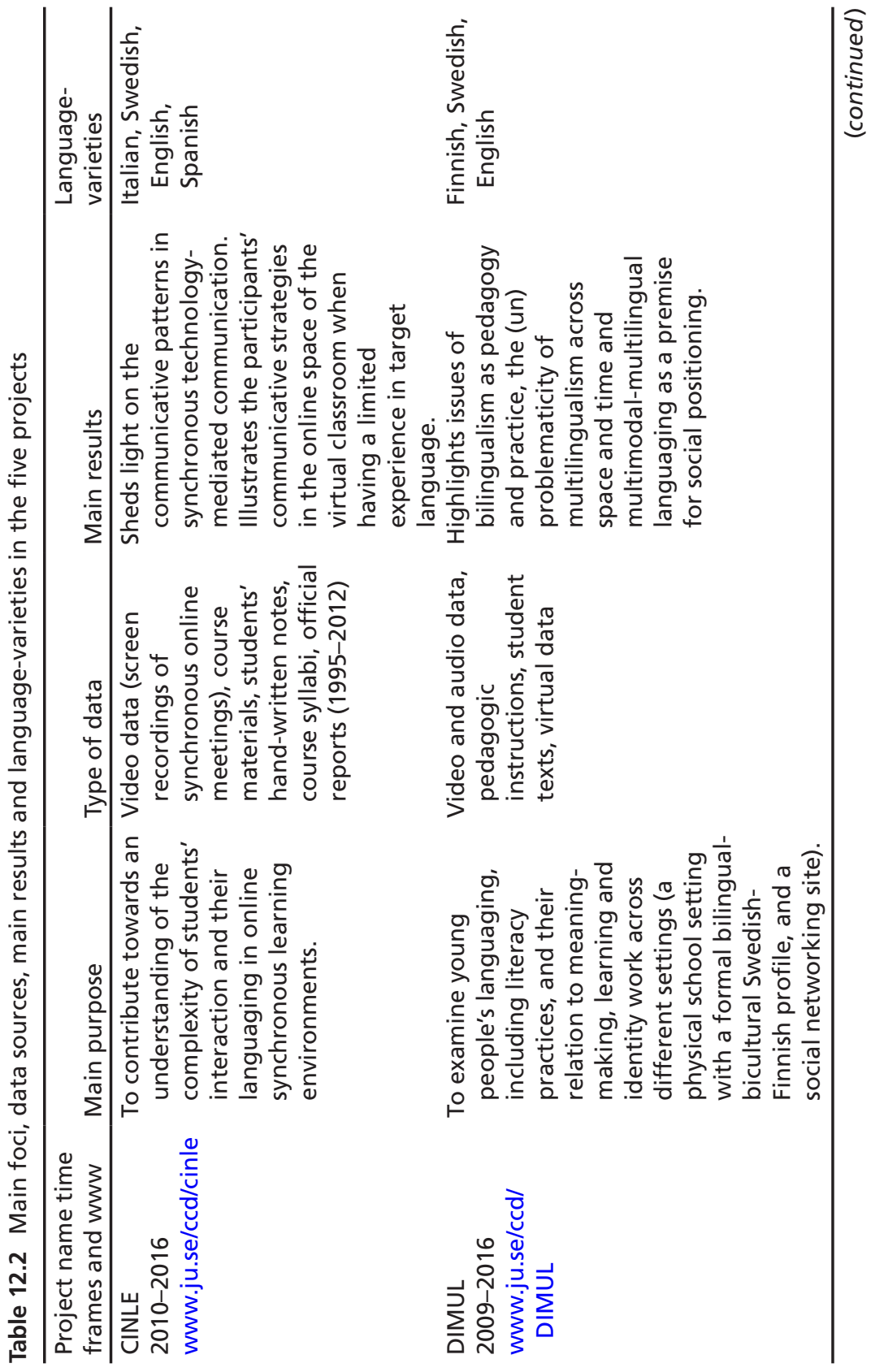




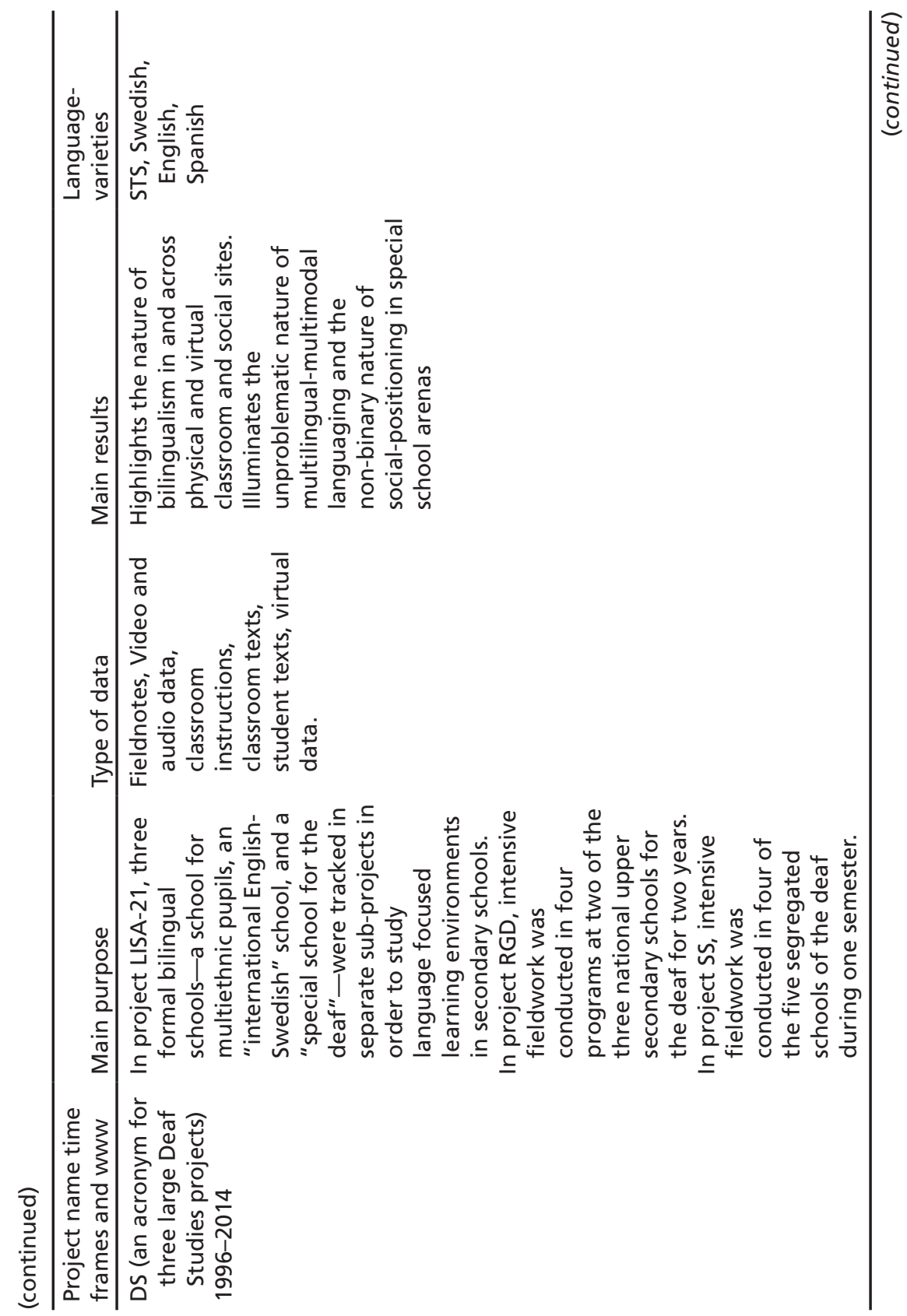




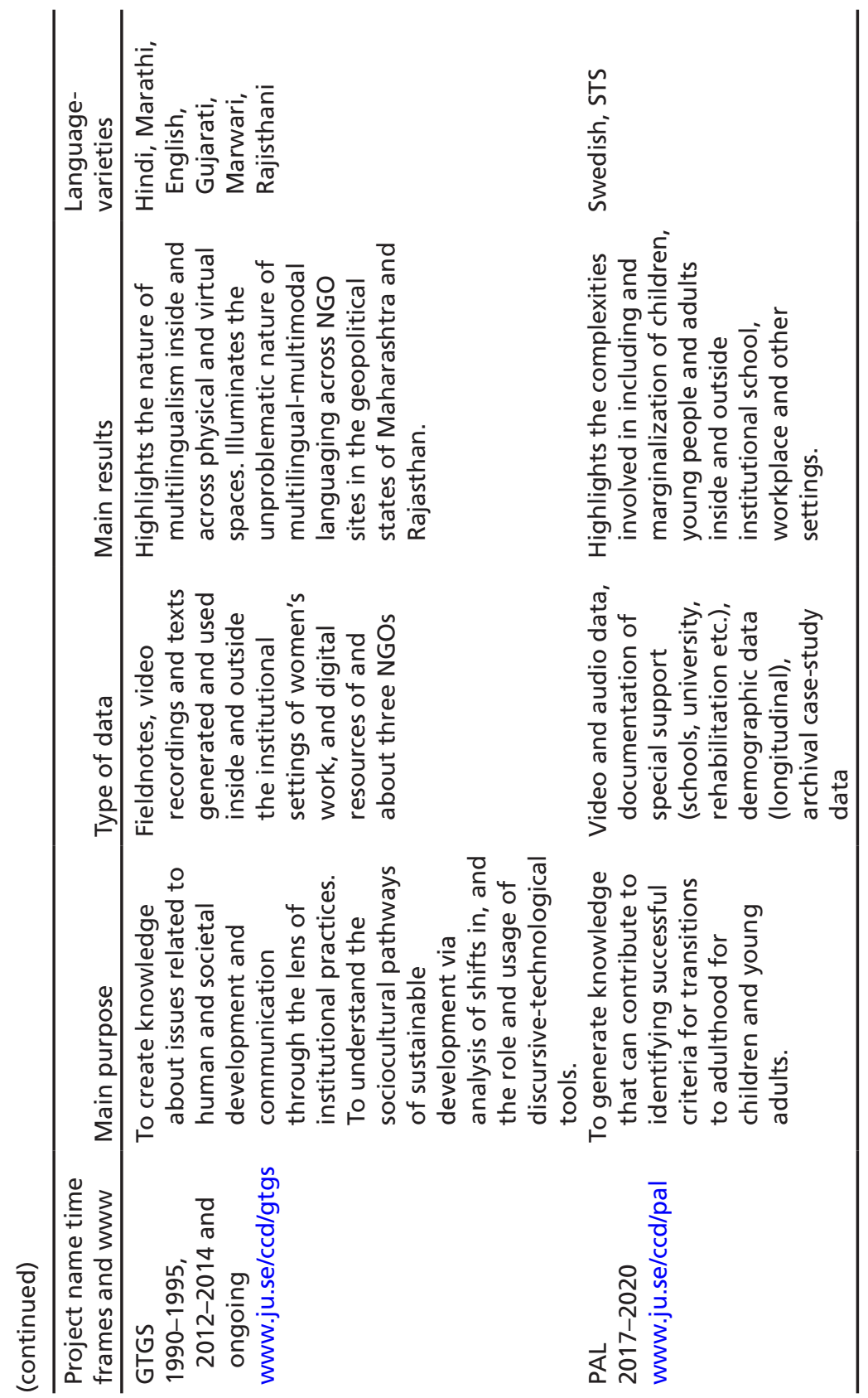




\section{References}

Androutsopoulos, J. (2008). Potentials and Limitations of Discourse-Centred Online Ethnography. Language @ Internet, 5, 1-20.

Asad, T. (1986). The Concept of Cultural Translation in British Social Anthropology. In J. Clifford \& G. E. Marcus (Eds.), Writing Culture. The Poetics and Politics of Ethnography (pp. 141-164). Berkeley: University of California Press.

Back, L. (2015). Why Everyday Life Matters: Class, Community and Making Life Livable. Sociology, 49(5), 820-836.

Bagga-Gupta, S. (1995). Human Development and Institutional Practices. Women, Child Care and the Mobile Creches. Linköping Studies in Arts and Science 130. Doctoral dissertation, Department of Communication Studies, Linköping University, Sweden.

Bagga-Gupta, S. (1999/2000). Visual Language Environments. Exploring Everyday Life and Literacies in Swedish Deaf Bilingual Schools. Visual Anthropology Review, 15(2), 95-120.

Bagga-Gupta, S. (2002). Explorations in Bilingual Instructional Interaction: A Sociocultural Perspective on Literacy. Journal of the European Association on Learning and Instruction, 5(2), 557-587.

Bagga-Gupta, S. (2004). Visually Oriented Bilingualism. Discursive and Technological Resources in Swedish Deaf Pedagogical Arenas. In V. Herreweghe \& M. Vermeerbergen (Eds.), To the Lexicon and Beyond. Sociolinguistics in European Deaf Communities, Volume 10 - The Sociolinguistics in Deaf Communities Series. Editor C Lucas (pp. 171-207). Washington, DC: Gallaudet University Press.

Bagga-Gupta, S. (2012a). Challenging Understandings of Bilingualism in the Language Sciences from the Lens of Research that Focuses Social Practices. In E. Hjörne, G. van der Aalsvoort, \& G. de Abreu (Eds.), Learning, Social Interaction and Diversity - Exploring School Practices (pp. 85-102). Rotterdam: Sense.

Bagga-Gupta, S. (2012b). Privileging Identity Positions and Multimodal Communication in Textual Practices: Intersectionality and the (Re)negotiation of Boundaries. In A. Pitkänen-Huhta \& L. Holm (Eds.), Literacy Practices in Transition. Perspectives from the Nordic Countries (pp. 75-100). Bristol: Multilingual Matters.

Bagga-Gupta, S. (2013). The Boundary-Turn. Relocating Language, Identity and Culture Through the Epistemological Lenses of Time, Space and Social 
Interactions. In I. Hasnain, S. Bagga-Gupta, \& S. Mohan (Eds.), Alternative Voices: (Re)searching Language, Culture and Identity... (pp. 28-49). Newcastleupon-Tyne: Cambridge Scholars Publishing.

Bagga-Gupta, S. (2014a). Languaging: Ways-of-Being-with-Words Across Disciplinary Boundaries and Empirical Sites. In H. Paulasto, H. Riionheimo, L. Meriläinen, \& M. Kok (Eds.), Language Contacts at the Crossroads of Disciplines (pp. 89-130). Newcastle-upon-Tyne: Cambridge Scholars Publishing.

Bagga-Gupta, S. (2014b). Performing and accounting language and identity: Agency as actors-in- (inter)action-with-tools. In P. Deters, Xuesong Gao, E. Miller \& G. Vitanova-Haralampiev (Eds.), Theorizing and Analyzing Agency in Second Language Learning: Interdisciplinary Approaches (pp. 113-132). Bristol: Multilingual Matters.

Bagga-Gupta, S. (2017a). Signed Languages in Bilingual Education. In: S. May (General Ed.), Encyclopedia of Language and Education. O. García and A. M.Y. Lin (eds.) Volume 5: Bilingual and Multilingual Education (pp. 131-145). Rotterdam: Springer.

Bagga-Gupta, S. (2017b). Language and Identity Beyond the Mainstream. Democratic and Equity Issues for and by Whom, Where, When and Why. Journal of the European Second Language Association, 1(1), 102-112. https:// doi.org/10.22599/jesla.22

Bagga-Gupta, S. (2017c). Languaging and Isms of Reinforced Boundaries Across Settings: Multidisciplinary Ethnographical Explorations. In D. J. Rivers \& K. Zotzmann (Eds.), Volume 11 Series Language and Social Life. -isms of Oppression in Language Education (pp. 203-229). Berlin: Mouton de Gruyter.

Bagga-Gupta, S. (2019a). Identity Positioning and Languaging in Deaf-Hearing Worlds: Some Insights from Studies of Segregated and Mainstream Educational Settings. In I. Leigh \& C. O'Brien (Eds.), Deaf Identities. Exploring New Frontiers. Oxford: Oxford University Press.

Bagga-Gupta, S. (2019b, in press). Learning Languaging matters. Contributions to a turn-on-turn reflexivity. In S. Bagga-Gupta, A. Golden, L. Holm, H. P. Laursen \& A. Pitkänen-Huhta (Eds.), Reconceptualizing Connections between Language, Literacy and Learning. Rotterdam: Springer.

Bagga-Gupta, S., Hansen, A. L., \& Feilberg, J. (Eds.). (2017). Identity Revisited and Reimagined. Empirical and Theoretical Contributions on Embodied Communication Across Time and Space. Rotterdam: Springer.

Bagga-Gupta, S., \& Messina Dahlberg, G. (2017). Mobilization of Nomenclature in the Language and Diversity Areas in Learning and Instruction. Paper at the 
invited symposium of SIG 21 at EARLI 2017, Education in the crossroads of economy and politics - Role of research in the advancement of public good, 29 August-2 September, Tampere, Finland.

Bagga-Gupta, S., \& Messina Dahlberg, G. (2018). Meaning-Making or Heterogeneity in the Areas of Language and Identity? The Case of Translanguaging and Nyanlända (Newly-Arrived) Across Time and Space. International Journal of Multilingualism, 15(4), 383-411.

Bakhtin, M. (1981). The Dialogic Imagination (C. Holmquist, Ed.). Austin: University of Texas Press.

Berger, P. L., \& Luckman, T. (1966). The Social Construction of Reality. A Treatise in the Sociology of Knowledge. New York: Penguin.

Byrd Clark, J., \& Dervin, F. (Eds.). (2014). Reflexivity in Language and Intercultural Education. Rethinking Multilingualism and Interculturality. London: Routledge.

Cerwonka, A., \& Malkki, L. H. (2007). Improvising Theory. Process and Temporality in Ethnographic Fieldwork. Chicago: University of Chicago Press. Clifford, J., \& Marcus, G. E. (Eds.). (1986). Writing Culture. The Poetics and Politics of Ethnography. Berkeley: University of California Press.

Comaroff, J. L., \& Comaroff, J. (2009). Ethnicity, Inc. Chicago Studies in Practices of Meaning. Chicago: University of Chicago Press.

Daiute, C. (2015). De-colonial Dialogues: Conversations Within and Across Worldviews. Discussion paper presented at the Invited Symposium "The Boundary Turn: Challenges in Researching and Practicing De-colonial Education and Community Development". EARLI 2015 conference, Limassol, Cyprus August 2015.

Denzin, N. K., \& Lincoln, Y. S. (Eds.). (2000). Handbook of Qualitative Research. Thousand Oaks, CA: Sage.

Deters, P., Gao, X., Miller, E., \& Vitanova-Haralampiev, G. (Eds.). (2014). Interdisciplinary Approaches to Theorizing and Analyzing Agency and Second Language Learning. Bristol: Multilingual Matters.

Donald, M. (2001). A mind so rare. The evolution of human consciousness. New York: Norton.

Emerson, R. M., Fretz, R. I., \& Shaw, L. L. (1995). Writing Ethnographic Fieldnotes (2nd ed.). Chicago: The University of Chicago Press.

Fabian, J. (1983). Time and the Other. How Anthropology Makes Its Object. New York: Columbia University Press.

Fabion, J. D., \& Marcus, G. E. (2009). Fieldwork Is Not What It Used to Be. Learning Anthropology's Method in a Time of Transition. Ithaca: Cornell University Press. 
Fanon, F. (1961). The Wretched of the Earth. New York: Grove Press.

Finnegan, R. (2015). Where Is Language? An Anthropologist's Questions on Language, Literature and Performance. New York: Bloomsbury.

Flewitt, R., R. Hampel, M. Hauck \& Lancaster, L. (2009). What are multimodal data and transcription? in Jewitt, C. (ed.), The Routledge Handbook of Multimodal Analysis (pp. 40-53). London: Routledge.

Gal, S. (2007). Multilingualism. In C. Llamas, L. Mullany, \& P. Stockwell (Eds.), The Routledge Companion to Sociolinguistics (pp. 149-157). New York: Routledge.

Gal, S., \& Irvine, J. T. (1995). The Boundaries of Languages and Disciplines: How Ideologies Construct Difference. Social Research, 62(4), 967-1001.

Garcia, O. (2009). Bilingual Education in the 21st Century: A Global Perspective. Oxford: Blackwell.

Garcia, O., \& Lin, A. (Eds.). (2015). Bilingual and Multilingual Education. Volume 5. Encyclopedia of Language and Education, General Editor Stephen May. Springer.

Goico, S. (2019). The Social Lives of Deaf Youth in Iquitos, Peru. Ph.D. dissertation, University of California, San Diego.

Goodwin, C. (1994). Professional Vision. American Anthropologist, 96, 606-633. Gramling, D. (2016). The Invention of Monolingualism. New York: Bloomsbury. Gynne, A. (2016). Languaging and Social Positioning in Multilingual School Practices - Studies of Sweden Finnish Middle School Years. Västerås: Mälardalen University.

Gynne, A. (2017). "Janne X was here”. Portraying identities and negotiating being and belonging in informal literacy practices. In: Bagga-Gupta, S., Aase Lyngvær Hansen, Julie Feilberg (Eds.), Identity Revisited and Reimagined: Empirical and Theoretical Contributions on Embodied Communication Across Time and Space (pp. 271-292). Rotterdam: Springer.

Gynne, A., \& Bagga-Gupta, S. (2013). Young People’s Language Usage and Identity Positioning: Chaining in "Bilingual" Educational Settings in Sweden. Linguistics and Education, 24(4), 479-496.

Gynne, A., \& Bagga-Gupta, S. (2015). Languaging in the Twenty-First Century. Exploring Varieties and Modalities in Literacies Inside and Outside Learning Spaces. Language and Education, 29(6), 509-526. https://doi.org/10.1080/0 9500782.2015 .1053812

Gynne, A., \& Bagga-Gupta, S. (2017). Chaining: the Use of Language Resources Including Literacies on the Move. Conference Skriv! Les! 2017, 9-11 May, Trondheim, Norway. 
Hansen, A. L. (2005). Communicative Practices in Visually Oriented Classrooms: A Study of a Model Education for Deaf Teacher Candidates. Unpublished Ph.D. thesis, NTNU University, Norway. 1005:132.

Hansen, A. L., \& Bagga-Gupta, S. (2017). Visually Oriented Multilingual Communication. Participation in Higher Education. Paper in the Symposium Participation and inclusion in educational settings. Issues and challenges. NNDR, Nordic Network on Disability Conference at Örebro, Sweden, 3-5 May.

Hasnain, I., Bagga-Gupta, S., \& Mohan, S. (2013). Alternative Voices: (Re) searching Language, Culture and Identity.... Newcastle-upon-Tyne: Cambridge Scholars Publishing.

Holmström, I. (2013). Learning by Hearing. Technological Framings for Participation. Örebro Studies in Education 42. Ph.D. dissertation, Örebro University, Sweden.

Hoppers, C. O. (2009). Research-Knowledge-Development: Emerging Perspectives in a Global Dimension. Keynote at the Educational Sciences Committees Resultatdialog 2009, Umeå University, Sweden.

Horst, H., \& Miller, D. (2012). Digital Anthropology. London: Bloomsbury.

Jewitt, C. (Ed.). (2009). The Routledge Handbook of Multimodal Analysis. London: Routledge.

Kotzines, R. V. (2010). Netnography. Doing Ethnographic Research Online. London: Sage.

Kress, G. (2003). Literacy in the New Media Age. London: Routledge. Kress, G., \& van Leeuven, T. (1996). Reading Images: The Grammar of Visual Design. London: Routledge.

Lave, J., \& Wenger, E. (1991). Situated Learning. Legitimate Peripheral Participation. Cambridge, MA: Cambridge University Press.

Leandri, P., \& Neumann, E. (2014). Introduction. Mobile Sociologies of Education. European Educational Research Journal, 131, 1-8.

Liddicoat, A. J. (2011). Enacting Participation: Hybrid Modalities in Online Video Conversation. In C. Develotte, R. Kern, \& M.-N. Lamy (Eds.), Dé-crire la conversation en ligne: le face à face distanciel (pp. 51-70). Lyon: ENS Éditions.

Linell, P. (2009). Rethinking Language, Mind, and World Dialogically. Interactional and Contextual Theories of Human Sense-Making. Charlotte, NC: Information Age Publishing.

Luff, P., Heath, C., Kuzuoka, H., Hindmarsh, J., Yamazaki, K., \& Oyama, S. (2003). Fractured Ecologies: Creating Environments for Collaboration. Human-Computer Interaction, 18, 51-84. 
Machin, D. (2013). What Is Multimodal Critical Discourse Studies? Critical Discourse Studies, 10(4), 347-355.

Marcus, G. E. (1986). Contemporary Problems of Ethnography in the Modern World System. In J. Clifford \& G. E. Marcus (Eds.), Writing Culture. The Poet-ics and Politics of Ethnography (pp. 165-193). Berkely, CA: University of California Press.

Marcus, G. E. (1995). Ethnography in/of the World System: The Emergence of Multi-Sited Ethnography. Annual Review of Anthropology, 24, 95-117.

Messina Dahlberg, G. (2015). Languaging in Virtual Learning Sites: Studies of Online Encounters in the Language-Focused Classroom. Doctoral dissertation, Örebro Studies in Education 49, Örebro University, Sweden.

Messina Dahlberg, G., \& Bagga-Gupta, S. (2014). Understanding Glocal Learning Spaces: An Empirical Study of Languaging and Transmigrant Positions in the Virtual Classroom. Learning, Media \& Technology, 39(4), 468-487.

Messina Dahlberg, G., \& Bagga-Gupta, S. (2015). Learning on-the-Go in Institutional Telecollaboration: Anthropological Perspectives on the Boundaries of Digital Spaces. In E. Dixon \& M. Thomas (Eds.), Researching Language Learner Interaction Online: From Social Media to MOOCs (Vol. 13, pp. 259-281). CALICO.

Messina Dahlberg, G., \& Bagga-Gupta, S. (2016). Mapping Languaging in Digital Spaces. Literacy Practices at Borderlands. Language Learning \& Technology, 20(3), 80-106.

Mignolo, W. D. (2012). Local Histories/Global Designs. Coloniallity, Subaltern Knowledges and Border Thinking. New Jersey: Princeton University Press.

Okely, J. (1996). Own or Other Culture. London: Routledge.

Paulasto, H., Riionheimo, H., Meriläinen, L., \& Kok, M. (Eds.). (2014). Language Contacts at the Crossroads of Disciplines. Newcastle-upon-Tyne: Cambridge Scholars Publishing.

Pavlenko, A. (2017). Superdiversity and Why It Isn't. Reflections on Terminological Innovations and Academic Branding. In S. Breidbach, L. Küster, \& B. Schmenk (Eds.), Sloganizations in Language Education Discourse. Bristol: Multilingual Matters.

Pink, S. (2007). Doing Visual Ethnography. London: Sage.

Pitkänen-Huhta, A., \& Holm, L. (Eds.). (2012). Literacy Practices in Transition. Perspectives from the Nordic Countries. Bristol: Multilingual Matters.

Säljö, R. (2005). Lärande och kulturella redskap: om lärprocesser och det kollektiva minnet. Lund: Studentlitteratur. 
Säljö, R. (2012). Literacy, Digital Literacy and Epistemic Practices: The Co-Evolution of Hybrid Minds and External Memory System. Nordic Journal of Digital Literacy, 12(1), 5-20.

Savransky, M. (2017). A Decolonial Imagination: Sociology, Anthropology and the Politics of Reality. Sociology, 51(1), 11-26.

Scollon, R., \& Scollon Wong, S. (2004). Nexus Analysis: Discourse and the Emerging Internet. London: Routledge.

St John, O. (2014). Approaching Classroom Interaction Dialogically: Studies of Everyday Encounters in a "Bilingual" Secondary School. Doctoral dissertation, Örebro University, Örebro.

Sturge, K. (1997). Translation Strategies in Ethnography. The Translator, 3(1), 21-38. https://doi.org/10.1080/13556509.1997.10798986

Tapio, E. (2013). A Nexus Analysis of English in the Everyday Life of FinSL Signers: A Multimodal View on Interaction. Oulu: Oulu University.

Vygotsky, L. S. (1934/1962). Thought and Language. Cambridge, MA: M.I.T Press.

Wertsch, J. (2002). Voices of Collective Remembering. Cambridge: Cambridge University Press.

Wertsch, J. V. (1998). Mind as Action. Oxford: Oxford University Press.

Open Access This chapter is licensed under the terms of the Creative Commons Attribution 4.0 International License (http://creativecommons.org/ licenses/by/4.0/), which permits use, sharing, adaptation, distribution and reproduction in any medium or format, as long as you give appropriate credit to the original author(s) and the source, provide a link to the Creative Commons licence and indicate if changes were made.

The images or other third party material in this chapter are included in the chapter's Creative Commons licence, unless indicated otherwise in a credit line to the material. If material is not included in the chapter's Creative Commons licence and your intended use is not permitted by statutory regulation or exceeds the permitted use, you will need to obtain permission directly from the copyright holder.

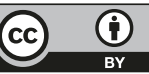

